\title{
Morphological and Physicochemical Characterization of Agglomerates of Titanium Dioxide Nanoparticles in Cell Culture Media
}

\author{
Verónica Freyre-Fonseca, ${ }^{1,2}$ Darío I. Téllez-Medina, ${ }^{1}$ Estefany I. Medina-Reyes, ${ }^{2}$ \\ Maribel Cornejo-Mazón, ${ }^{3}$ Edgar O. López-Villegas, ${ }^{4}$ Liliana Alamilla-Beltrán, ${ }^{1}$ \\ José Ocotlán-Flores, ${ }^{5}$ Yolanda I. Chirino, ${ }^{2}$ and Gustavo F. Gutiérrez-López ${ }^{1}$ \\ ${ }^{1}$ Departamento de Graduados e Investigación en Alimentos, Departamento de Ingeniería Bioquímica, \\ Escuela Nacional de Ciencias Biológicas, Instituto Politécnico Nacional, Carpio y Plan de Ayala, s/n, 11340 México, DF, Mexico \\ ${ }^{2}$ Facultad de Estudios Superiores-Iztacala, Universidad Nacional Autónoma de México, Avenida de los Barrios No. 1, \\ 54090 Los Reyes Iztacala, MEX, Mexico \\ ${ }^{3}$ Departamento de Biofísica, Escuela Nacional de Ciencias Biológicas, Instituto Politécnico Nacional, Carpio y Plan de Ayala, \\ s/n, 11340 México, DF, Mexico \\ ${ }^{4}$ Central de Microscopía Escuela Nacional de Ciencias Biológicas, Instituto Politécnico Nacional, Carpio y Plan de Ayala, \\ s/n, 11340 México, DF, Mexico \\ ${ }^{5}$ Centro de Ciencias Aplicadas y Desarrollo Tecnológico, Universidad Autónoma de México, Ciudad Universitaria, \\ Circuito Exterior s/n, 04510 México, DF, Mexico
}

Correspondence should be addressed to Gustavo F. Gutiérrez-López; gusfgl@gmail.com

Received 31 August 2015; Revised 18 November 2015; Accepted 22 November 2015

Academic Editor: Prashant Kumar

Copyright (C) 2016 Verónica Freyre-Fonseca et al. This is an open access article distributed under the Creative Commons Attribution License, which permits unrestricted use, distribution, and reproduction in any medium, provided the original work is properly cited.

Titanium dioxide nanoparticles $\left(\mathrm{TiO}_{2} \mathrm{NP}\right)$ are possible carcinogenic materials (2B-IARC) and their toxicity depends on shape, size, and electrical charge of primary NP and on the system formed by NP media. The aim of this work was to characterize agglomerates of three $\mathrm{TiO}_{2} \mathrm{NP}$ by evaluating their morphometry, stability, and zeta potential $(\zeta)$ in liquid media and their changes with time. Sizes of agglomerates by dynamic light scattering (DLS) resulted to be 10-50 times larger than those obtained by digital image analysis (DIA) given the charged zone around particles. Fractal dimension (FD) was highest for agglomerates of spheres and belts in F12K, and in E171 in FBS media. E171 and belts increased FD with time. At time zero, using water as dispersant FD was larger for agglomerates of spheres than for of E171. Belts suspended in water had the smallest values of circularity (Ci) which was approximately unchanged with time. All dispersions had $\zeta$ values around $-30 \mathrm{mV}$ at physiological $\mathrm{pH}$ (7.4) and dispersions of NP in water and FBS showed maximum stability (Turbiscan Lab analysis). Results help in understanding the complex NP geometry-size-stability relationships when performing in vivo and in vitro environmental-toxicity works and help in supporting decisions on the usage of $\mathrm{TiO}_{2} \mathrm{NP}$

\section{Introduction}

Titanium dioxide $\left(\mathrm{TiO}_{2}\right)$ nanoparticles (NP) in the form of anatase are a white synthetic powder used in a wide range of nanotechnology applications given their anticorrosion and photocatalytic properties and they are difficult to dispose [1]. Nearly $70 \%$ of all $\mathrm{TiO}_{2} \mathrm{NP}$ produced in the form of spheres are used as a pigment in paints, but they are also used in glazes, enamels, plastics, paper, fibers, pharmaceuticals, cosmetics, and toothpaste [1]. They are particularly used in cosmetic and skin care products, for example, in sunscreens in which they help in protecting the skin against UV light damage. Due to their photocatalytic properties, $\mathrm{TiO}_{2} \mathrm{NP}$ have also been used in wastewater treatment $[2,3]$ and in solar cells $[1,4]$. For aquatic environments, it is difficult to determine their potential ecotoxicological impacts in fish 
given the lack of understanding of the complex interactions existing in these systems and of data on the bioavailability of $\mathrm{TiO}_{2} \mathrm{NP}$ in aquatic environments [5]. Other $\mathrm{TiO}_{2}$ types, such as nanobelts, include antimicrobial, environmental, and medical applications [1]. Particularly, E171 particles have been used as an additive in foodstuffs in sugar products, candies, chewing gum, coffee whitener, and pet food [1]. The use of $\mathrm{TiO}_{2}$ has been classified as safe by the Food and Drug Administration (FDA) $(<1 \% \mathrm{w} / \mathrm{w}$ in food applications) and the European Food Safety Authority (EFSA) as E171; children are subjected to higher exposure levels (around $2 \mathrm{mg}$ of $\mathrm{TiO}_{2}$ per $\mathrm{kg}$ /day) than adults (around $1 \mathrm{mg}$ of $\mathrm{TiO}_{2}$ per $\mathrm{kg}$ /day) [1]. However, other agencies such as the IARC classify $\mathrm{TiO}_{2}$ as a possible carcinogenic compound (group 2B) to humans when entering human body by respiratory paths. The NIOSH have recommended that concentration of this compound should not exceed $0.3 \mathrm{mg}$ of $\mathrm{TiO}_{2} \mathrm{NP} / \mathrm{m}^{3}$ in working spaces.

There are various reports on the effects of chronic human exposure to $\mathrm{TiO}_{2} \mathrm{NP}$ such as oxidative stress [6], DNA damage [7,8], cell injury [9], enhancement of Crohn's disease symptoms [10, 11], respiratory damage and asthma [12], and nephrotoxic effects [13]. The size of NP is also important and, in this respect, a correlation between particle size, chronic exposure to $\mathrm{TiO}_{2} \mathrm{NP}$, and lung injury in Wistar rats exposed to $\mathrm{TiO}_{2} \mathrm{NP}(20-250 \mathrm{~nm})$ was found [14]. Authors have suggested that the surface area of the retained particles was a good dose determinant [14]. Moreover, when performing a number of in vitro and in vivo experiments, the formation of NP media agglomerates determines the size and form in which $\mathrm{TiO}_{2}$ first contact cells and tissues so that morphometric and physicochemical characteristics of such agglomerates importantly determine the effects of $\mathrm{TiO}_{2}$ on those cells and tissues. The various effects in humans, rats, and mice exposed to $\mathrm{TiO}_{2} \mathrm{NP}$ are directly related to the properties of the primary NP and their agglomerates, such as shape, size, electrical charge, and surface [15-17]. It has been recognized that the smaller the agglomerates are, the easier they will reach deeper zones in the organism and disperse in body fluids [18]. In vitro testing has been used to determine the potential toxicity of NP before proceeding with in vivo studies [19]. Shape and size are critical in phagocytosis processes [20] and it has been observed that ellipsoidal particles showed a larger adhesion to endothelial cells in blood vessels than the spherical ones during flow dynamic studies [21].

The works mentioned above suggest that there is an intrinsic relationship between the properties of the NP media and their biological effects. Most of the recent toxicity studies have focused on physicochemical properties of the NP (in particular in the form of spheres) and on approaches focused to predict how $\mathrm{TiO}_{2} \mathrm{NP}$ arrays enter the respiratory system in contaminated environments or when particles such as E171 (used in food applications) pass in the digestive system $[6,14,16,22,23]$.

Assembling of $\mathrm{TiO}_{2} \mathrm{NP}$ has been related to their size, morphology, $\zeta, \mathrm{pH}$, and surface area of agglomerates and primary particles [13]. Information on the morphology of such agglomerates has not been fully considered when trying to understand key function issues of interfaces such as cell internalization mechanisms after environmental exposure.
Morphology and surface properties of the $\mathrm{TiO}_{2} \mathrm{NP}$ agglomerates could help to understand the mechanisms of such internalization into cells and to identify the type of receptors involved in the internalization processes and determining the triggering of different signaling cascades in the cells. For instance, it has been reported that when NP have a high aspect ratio, the tendency of agglomerates to adhere to cell walls is larger than when this parameter is low [21].

Size, contact area, and morphology of NP agglomerates are influenced by the media in which they are suspended and by the corresponding NP size, $\mathrm{pH}$, stability, and $\zeta$ which must be evaluated in dispersions formed in particular media $[16$, 23]. Information about morphology of NP can be obtained by means of digital image analysis (DIA) which is the construction of explicit, meaningful, and quantitative descriptions of objects from captured images [24] as, for example, for individual particles or for their respective agglomerates [25]. DIA complements common microscopy observations by allowing the quantification of shape and size features [26]. This tool has been used for studying crystal shapes [27], in order to characterize materials such as granulated powder grains of pharmaceutical microparticles [28], as well as describe the morphology of strontium molybdate agglomerates [29] as well as study a number of biological phenomena such as angiogenesis [30]. The principle of this technique is the digitalization of an image into picture elements (pixels) and further extraction, processing, and classification of obtained data [31-33]. Stability with time of dispersions, on the other hand, has been evaluated by light retrodispersion techniques such as those based in the use of the Turbiscan Lab. Changes of physicochemical and morphometric characteristics of agglomerates influence their role in their physiological effects such as those related with the binding with molecules such as proteins thus forming the so called protein corona [34-36]. The aim of this work was to study size, morphology, $\zeta$, and stability with time of three types of $\mathrm{TiO}_{2} \mathrm{NP}$ agglomerates in different media used in toxicology and environmental in vivo and in vitro studies.

\section{Material and Methods}

2.1. Titanium Dioxide Nanoparticles $\left(\mathrm{TiO}_{2} \mathrm{NP}\right)$. Three types of $\mathrm{TiO}_{2} \mathrm{NP}$ were used in this study: anatase from Sigma Aldrich (Cat \# 637254) <25 nm particle size, 99.7\% purity, E171 kindly donated by Sensient Colors (México), and belts NP from the Nanotechnology and Nanostructured Materials Laboratory facilities of CCADET-UNAM, México. Culture media used were, F12 Kaighn's modification (F12K Kaighn's) Sigma Aldrich \# N35 20, fetal bovine serum (FBS) (GIBCO 16000044), and the combination $(1: 10)$ of F12K and FBS media. Control samples were prepared by using Milli-Q (type-1) water. All measurements of physicochemical and morphological characteristics of the agglomerates were made at time zero and subsequently at 180 and $1440 \mathrm{~min}$ of incubation time. These times were selected based on the fact that it has been reported that internalization into cells in in vitro systems has been reported to take place within 180$1440 \mathrm{~min}$ (24 h) [46]. 
2.2. Microscopy Images. Images of primary $\mathrm{TiO}_{2} \mathrm{NP}$ were obtained by scanning electron microscopy (SEM) (QUANTA FEG 3D), 5000x, $5 \mathrm{kV}$, and 26 pixels $/ \mathrm{nm}^{2}$. Images of agglomerates $\left(75000 \mathrm{x}, 60 \mathrm{kV}\right.$, and 0.533 pixels $\left./ \mathrm{nm}^{2}\right)$ were captured by transmission electron microscopy (TEM) (JEOL-JEM 1010, JEOL, Japan).

2.3. $\zeta$ and Hydrodynamic Diameter of Agglomerates. $\zeta$ values of the formed agglomerates were obtained by using a Zeta Plus analyzer (Brookhaven, USA) and their size as hydrodynamic diameter was evaluated by dynamic light scattering (DLS) using a Zetasizer Nano (Malvern, UK) instrument. Prior to DLS evaluation, $1 \mathrm{mg}$ of $\mathrm{TiO}_{2} \mathrm{NP}$ was suspended in $1 \mathrm{~mL}$ of Milli-Q type-1 water and sonicated for 30 minutes at $40 \mathrm{~Hz}$ and $2.4 \mu \mathrm{L}$ aliquots were added to the media so that the final concentration of $\mathrm{TiO}_{2} \mathrm{NP}$ was $3.43 \times 10^{-3} \mathrm{mg} / \mu \mathrm{L}$. All measurements were carried out at $23 \pm 1^{\circ} \mathrm{C}$ and at $\mathrm{pH} 7.4$ (physiological $\mathrm{pH}$ value).

$\zeta$ titration curves for each type of $\mathrm{TiO}_{2} \mathrm{NP}$ in the different media $\left(\mathrm{H}_{2} \mathrm{O}, \mathrm{FBS}, \mathrm{F} 12 \mathrm{~K}\right.$, and $\left.\mathrm{F} 12 \mathrm{~K}+\mathrm{FBS}\right)$ were constructed by varying the $\mathrm{pH}$ with the necessary amounts of $25 \mathrm{M} \mathrm{HCl}$ and $\mathrm{NaOH}[15]$.

2.4. Backscattering and Transmission Profiles (Turbiscan Lab Stability Analysis). A Turbiscan Lab Expert optical analyzer was used to determine stability of the different $\mathrm{TiO}_{2} \mathrm{NP}$ in the various media used as the variation of backscattering $(\Delta \mathrm{BS})$ and transmission $(\Delta T)$ profiles as reported elsewhere [3436]. These parameters are calculated by obtaining differences in light backscattering and transmission intensities during time. Kinetics of $\Delta \mathrm{BS}$ and of $\Delta T$ profiles were carried out during $180 \mathrm{~min}$ (15-minute intervals) [36].

2.5. Digital Image Analysis. Digital image analysis was carried out by means of the Image J 1.43 software (National Institutes of Health, USA). In this sense, $1 \mathrm{mg}$ of $\mathrm{TiO}_{2} \mathrm{NP}$ was suspended in $1 \mathrm{~mL}$ of Milli-Q type-1 water and sonicated for 30 minutes at $40 \mathrm{~Hz}$ and $2.4 \mu \mathrm{L}$ aliquots were added to the media so that the final concentration of $\mathrm{TiO}_{2} \mathrm{NP}$ was $3.43 \times 10^{-3} \mathrm{mg} / \mu \mathrm{L}$; then $30 \mu \mathrm{L}$ was pipetted in a grilled Formvar/carbon 100 copper meshes and, after 1 minute, they were blotted with tissue paper to eliminate the excess of liquid by using Whatmann paper and left overnight before TEM images were captured and converted to binary maps using automatic thresholding ( 255 white field). The following morphometric parameters were evaluated for NP formed agglomerates in each media: projected area $(A)$, perimeter $(P)$, circularity $(\mathrm{Ci})$, Feret diameter $(\mathrm{Fe})$, and aspect ratio (AR). Quantification of areas was carried out by means of the software as the sum of the individual areas of the pixels composing the object while the perimeter was obtained by adding the sizes of the pixels forming the image contour. The $\mathrm{Ci}$ of the agglomerates was measured as the ratio area/perimeter [47]. The Fe was determined as the maximum distance between two extremes of the object [31] and the AR as the relationship between the maximum and the minimum perpendicular axis of the object. Fractal dimension (FD) was evaluated by using the box counting method, that is, the amount of boxes $(N(\varepsilon))$ of different sizes $(\varepsilon)$ that were in contact with the perimeter of the agglomerate by using a virtual grid. FD was then calculated as the slope of the straight line, $\log N(\varepsilon)$ versus $\log (\varepsilon)$ [48]. All descriptors were evaluated for $2 \mathrm{D}$ images corresponding to $3 \mathrm{D}$ objects which have been customary practice in this type of analysis [49].

For a fractal object, its linear characteristic dimension is, in this case, the Feret diameter $(\mathrm{Fe})$ and a function of the area of the object or Fractal area, $A_{\mathrm{F}}$, can be related to Fe through a power law expression of the type given by $[50,51]$

$$
A_{\mathrm{F}} \alpha \mathrm{Fe} \mathrm{FD}^{\mathrm{FD}} \text {. }
$$

This proportion was applied to the corresponding FD values of the agglomerates for each $\mathrm{TiO}_{2} \mathrm{NP}$ used, and correlations (Pearson) between $A_{\mathrm{F}}$ and $\mathrm{Fe}^{\mathrm{FD}}$ were evaluated.

2.6. Statistical Analysis. The resulting image analysis parameters were statistically analyzed by means of the Prism Graphpad software (USA). One-way ANOVA analysis was carried out by using Bonferroni's tests for contrasting means and considering a significance level of $2 \alpha=0.05$.

\section{Results and Discussion}

3.1. Hydrodynamic Diameter and $\zeta$ Potential. Different manners of agglomeration were observed for each type of $\mathrm{TiO}_{2}$ $\mathrm{NP}$ in the studied media, giving place to a variety of sizes and morphologies of agglomerates that will have a marked influence on their environmental activity. No correlation was found between the smallest and the largest sizes of agglomerates formed in each media with the type of NP in the initial sample $(0 \mathrm{~min})$ which was due to different kind, magnitude, and interactions between particles and media $[34,35]$. The appearance of each type of primary NP is observed in Figure 1. Hydrodynamic diameters (HD) of $\mathrm{TiO}_{2}$ $\mathrm{NP}$ agglomerates formed in the four media are presented in Figure 2. All agglomerates showed marked increments in size followed by a fluctuating behavior of this parameter (Figure 2) which might be due to complex phenomena related with the disruption and to the building up of the soft and hard protein corona [36]. Also, all agglomerates showed larger sizes as compared with the initial ones at 180 and $1440 \mathrm{~min}$ indicating that a dynamic interaction $\mathrm{TiO}_{2}$-media prevailed during the experiment. These oscillating behaviors have been reported for a number of different NP in different media $[36,52]$. Sizes (as Feret diameters) of agglomerates measured by DLS were larger (10-50 times) than those evaluated by DIA as it was previously reported by other authors [53], who found similar differences when characterizing $\mathrm{TiO}_{2}$ spheres $\mathrm{NP}, \mathrm{Al}_{2} \mathrm{O}_{3} \mathrm{NP}$, and $\mathrm{SiO}_{2}$ NP suspended in FBS media. This difference was attributed by these authors to the electrical charged layer formed around the particles considered for the DIA experiments. The thickness of this layer is considered when obtaining the $\mathrm{HD}$ values and no correlation was found between the smallest and largest sizes of agglomerates formed in each media and the shape of the NP which was attributed to different magnitudes and types of interactions between particles and media. The composition of the media 


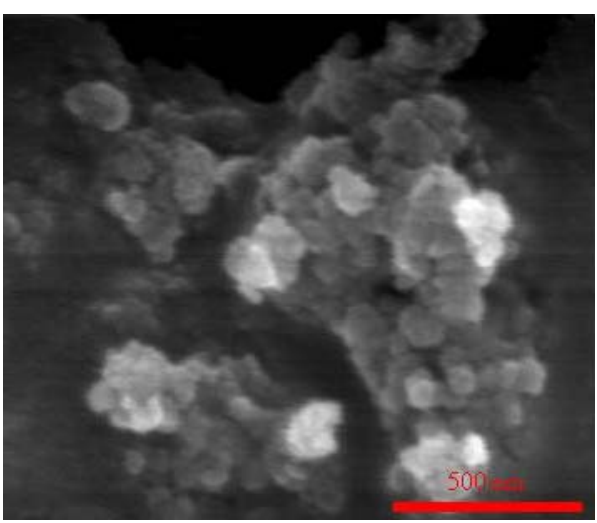

(a)

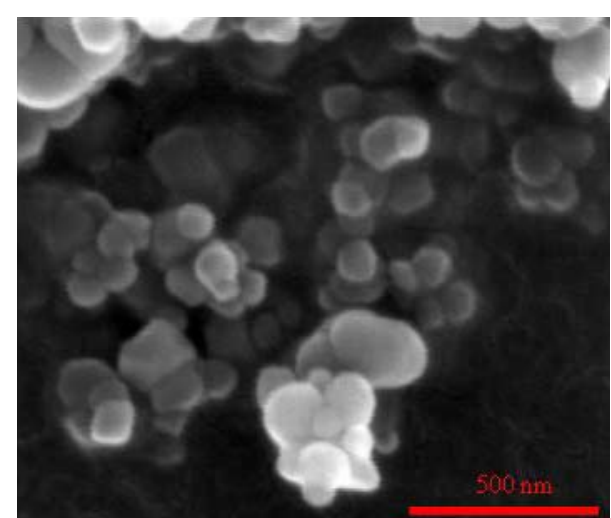

(b)

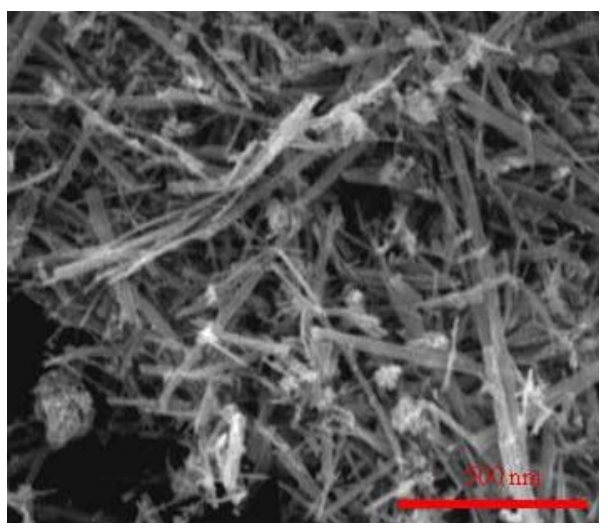

(c)

FIGURE 1: Scanning electron microscopy images of primary $\mathrm{TiO}_{2}$ NP. (a) Spheres, (b) E171, and (c) belts (5000x $5 \mathrm{kV}$ ).

promotes a number of interactions on the surface of $\mathrm{TiO}_{2}$ $\mathrm{NP}$, inducing the modification of interfaces, formed mainly by the protein fraction of the media around the particles $[16,23]$ which may change the average and distribution of the sizes of the agglomerates (Figure 2). The smallest sizes of agglomerate evaluated by DLS were found for spheres and belts in FBS media which has been reported to be a good dispersant [23], followed by belts particles in FBS and finally by spheres in water. These findings could indicate that media rich in albumin and fibrinogen such as blood would enable internalization of belts and E171 particles by endothelial cells.

The $\zeta$ value of the E171 dispersions was higher than that for belts and spheres (Figure 3 ). In particular, the size and $\zeta$ of $\mathrm{TiO}_{2} \mathrm{NP}$ dispersed in $\mathrm{H}_{2} \mathrm{O}(209 \pm 9 \mathrm{~nm}$ and $30.2 \mathrm{mV})$ at zero time, BEGM $(833 \pm 115 \mathrm{~nm}$ and $-9.4 \pm 0.8 \mathrm{mV})$, and DMEM media $(843 \pm 69 \mathrm{~nm}$ and $-7.4 \mathrm{mV})$ were reported [22]. Additionally, the sizes of three types of spherical $\mathrm{TiO}_{2} \mathrm{NP}$ dispersed in DMEM $+10 \%$ FBS were also evaluated and sizes of agglomerates from 5.8 to $14.6 \mathrm{~nm}$ were found [54]. Also, $\zeta$ values around $-15 \mathrm{mV}$ for agglomerates of $\mathrm{TiO}_{2} \mathrm{NP}$ spheres dispersed in $\mathrm{H}_{2} \mathrm{O}$ were found [15] and authors also reported values of $-9 \pm 1 \mathrm{mV}$ in agglomerates of $\mathrm{TiO}_{2} \mathrm{NP}$ spheres suspended in RPMI $+10 \%$ FBS media, while, in the present work, $\zeta$ of agglomerates of spherical $\mathrm{TiO}_{2} \mathrm{NP}$ dispersed in
$\mathrm{H}_{2} \mathrm{O}$ was $-16.2 \pm 1 \mathrm{mV}$ and that of the agglomerates of E171 dispersed in F12K + FBS media was $-30.5 \pm 2 \mathrm{mV}$ at zero time. The highest $\zeta$ value of the dispersion was found for E171 NP in water with a value of $-49.3 \pm 1.9 \mathrm{mV}$. $\zeta$ of spheres increased, from $-5.8 \mathrm{mV}$ in single F12K and FBS media, to $-20.9 \pm$ $0.7 \mathrm{mV}$ for the F12K + FBS, while the $\zeta$ of E171 increased from $-21 \mathrm{mV}$ for single F12K and FBS media, to $-30.5 \mathrm{mV}$ when using the mixture of F12K and FBS media. Stability of $\zeta$ with time can be observed in Figure 3. It is noteworthy that, for all systems, this parameter showed maximum stability at $180 \mathrm{~min}$ and fluctuated at other time intervals. It has been reported [46] that internalization of agglomerates to cells in in vitro systems happens within $180 \mathrm{~min}$. It is noteworthy that increments in hydrodynamic diameter of agglomerates in F12K and F12K + FBS at 180 min were related to $\zeta$ decrements. This was expected given the small proportion (10\%) of FBS in F12K + FBS media. $\zeta$ variation with $\mathrm{pH}$ was determined by constructing titration curves for each media and type of NP (Figure 4). No important differences were found between the isoelectric points for the different types of $\mathrm{TiO}_{2} \mathrm{NP}$ when they were dispersed in the colloidal system (except for water), having an average isoelectric point (IEP) of 4-6. The IEP of anatase and rutile Degussa $\mathrm{TiO}_{2} \mathrm{NP}$ dispersed in water and $\mathrm{NaCl}$ solutions was studied by different authors 

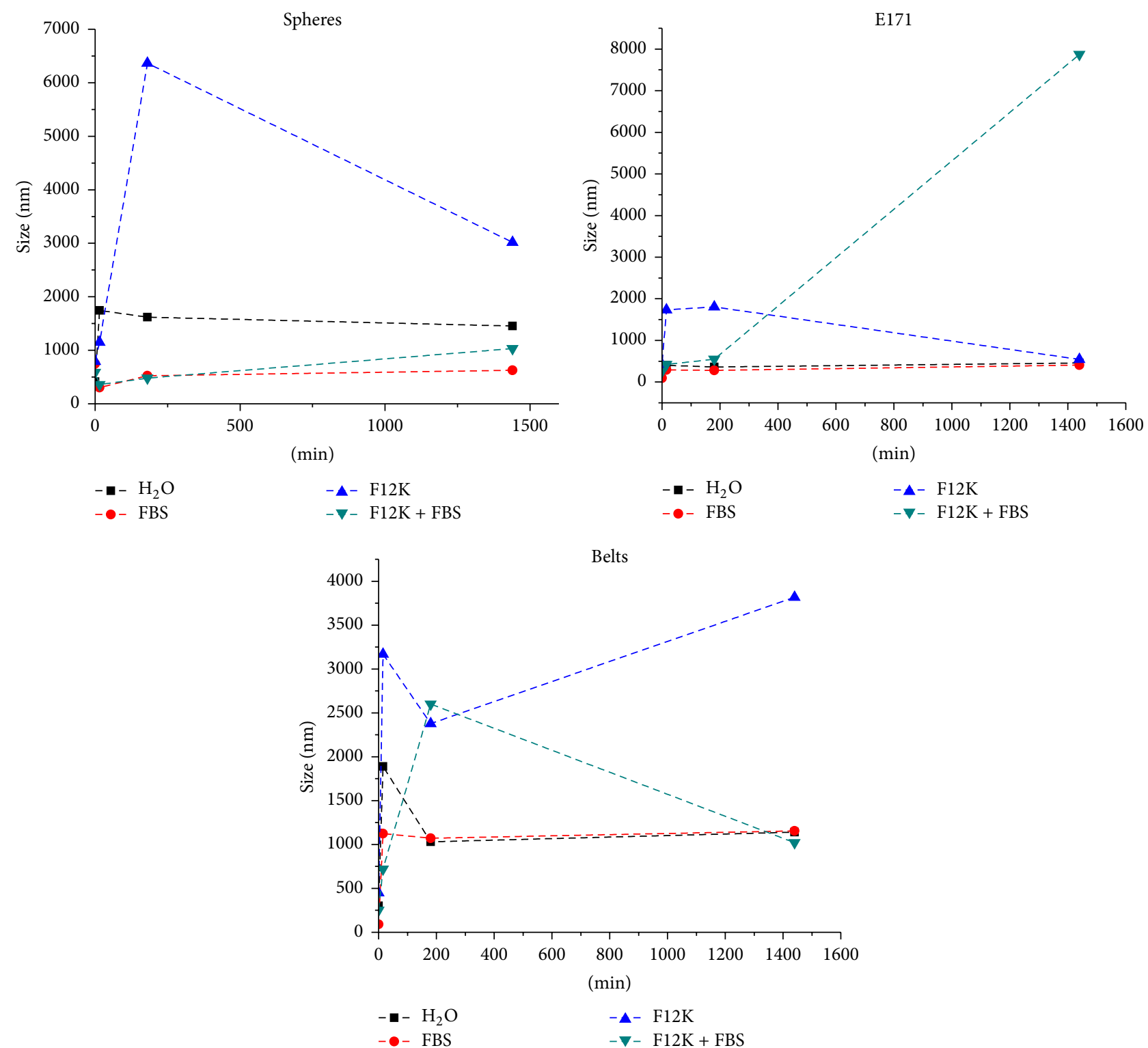

Figure 2: Time curves of hydrodynamic diameter of spheres, E171, and belts $\mathrm{TiO}_{2} \mathrm{NP}$ agglomerates suspended in different media.

$[22,55,56]$ who found isoelectric $\mathrm{pH}$ values varying from 2.9 to 6.9 [15]. In the present study, the IEP obtained when $\mathrm{TiO}_{2} \mathrm{NP}$ dispersed in water was around 2 for all media used. $\zeta$ values found for $\mathrm{TiO}_{2} \mathrm{NP}$ suspensions (except for dispersions in water) at physiological pH (7.4) were as E171 $<$ belts < spheres so that, at physiological conditions, E171 agglomerates will precipitate easier than those formed by spheres and, consequently, accumulate when contacting cells. However, spheres and belts dispersions had low negative $\zeta$ values at $\mathrm{pH}>10$. The same trend was observed for E171 dispersions at $\mathrm{pH} \approx 12$ as well as for belts suspended in $\mathrm{F} 12 \mathrm{~K}$ and $\mathrm{F} 12 \mathrm{~K}+\mathrm{FBS}$ at $\mathrm{pH} \approx 10$, and for $\mathrm{TiO}_{2}$ suspended in $\mathrm{F} 12 \mathrm{~K}$ at $\mathrm{pH} \approx 12$. Also for all types of $\mathrm{TiO}_{2} \mathrm{NP}$ dispersions, a low negative $\zeta$ region was observed for dispersions in $\mathrm{H}_{2} \mathrm{O}$ at $\mathrm{pH} \approx 3$ while, in all the other media at this $\mathrm{pH}$, all the agglomerates formed suspensions with $\zeta$ values $<30 \mathrm{mV}$. Negative $\zeta$ values (associated with negative particles charge) indicate a desorption of protons from the surface of the particle [57-59].

Size, shape, and $\zeta$ are distinctive characteristics of each NP system and this type of studies is recommended for the design of in vivo and in vitro experiments directed to various toxicological related studies. Morphology of NP influences their shape and self-assembly and thus their $\zeta$ at different $\mathrm{pH}$ values [60]. High and low $\mathrm{pH}$ values induced the formation of agglomerates having different shapes which explained the differences found among the titration curves of the agglomerates formed with different types of $\mathrm{TiO}_{2} \mathrm{NP}$ 

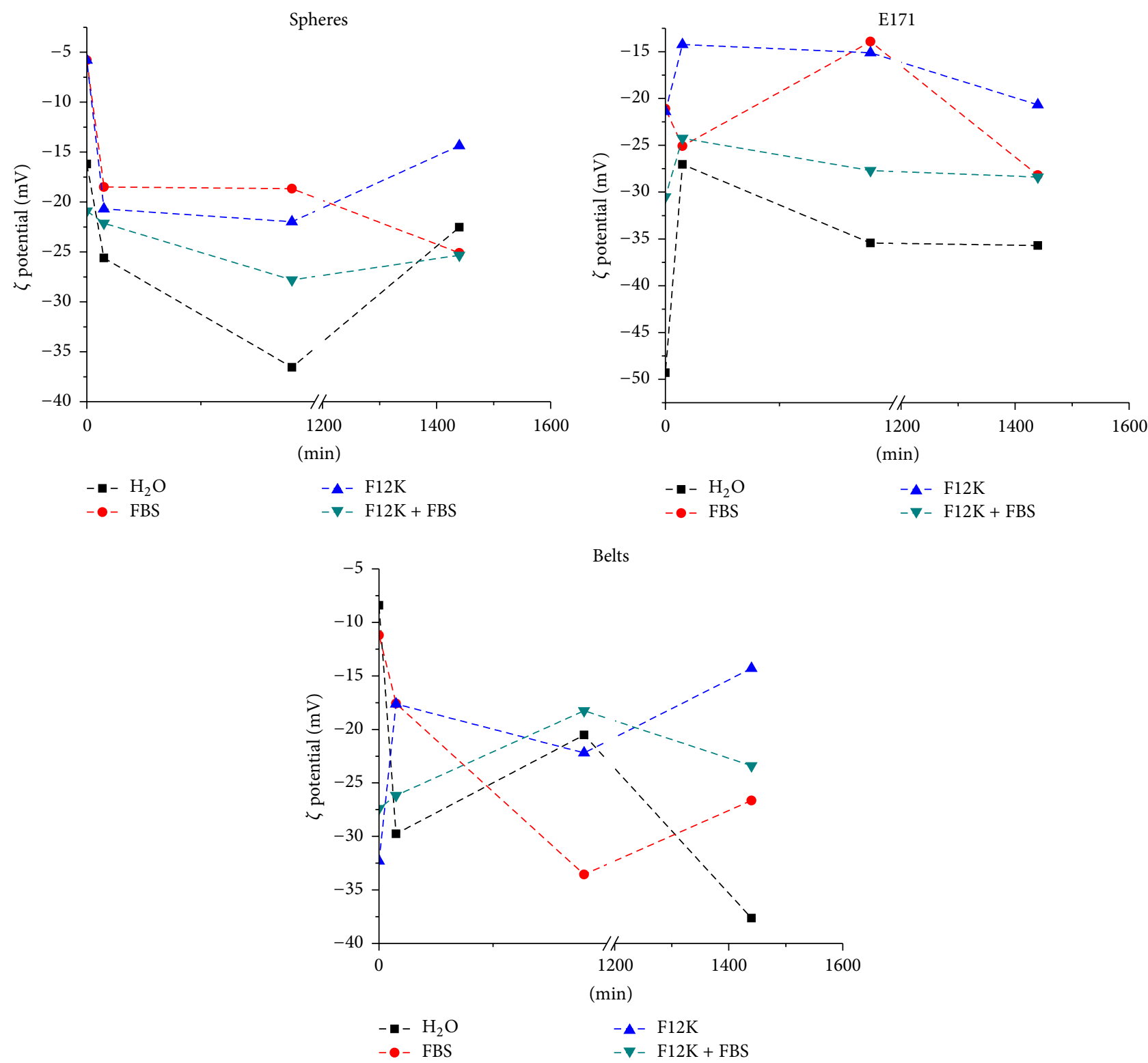

FIgUre 3: Time curves of $\zeta$ of spheres, E171, and belts $\mathrm{TiO}_{2} \mathrm{NP}$ agglomerates suspended in different media.

[60]. Morphometry, stability, and $\zeta$ of $\mathrm{TiO}_{2} \mathrm{NP}$ can help to determine if they are prone to be transported by physiological fluids or accumulated in body tissues [21].

The HD size and surface electric charge of NP have marked effects on the way in which an organism responds to $\mathrm{TiO}_{2}$ exposure. It was observed that surface charge of NP contributed to determining the blood brain barrier integrity and its permeability [61].

\subsection{Backscattering and Transmission Profiles (Turbiscan Lab} Stability Analysis). $\Delta \mathrm{BS}$ and $\Delta T$ for the different $\mathrm{TiO}_{2} \mathrm{NP}$ media systems used are reported in Figure 5. It is possible to observe that dispersions of $\mathrm{TiO}_{2} \mathrm{NP}$ in water and in FBS showed the maximum stability for 180 min since they presented a lower intensity of $\Delta \mathrm{BS}$ and $\Delta T$ (negative and positive peaks, resp.) corresponding to top and bottom of Turbiscan cell than those corresponding to the other media used so that these agglomerates after internalization will have the tendency to remain in suspension (thus to spread) within structures containing serum such as in the blood vessels. Marked stability (measured by $\zeta$ ) of $\mathrm{TiO}_{2} \mathrm{NP}$ in these media has also been reported by Allouni et al. (2009) [15]. Protein adsorption to particles often plays a decisive role in dispersion stability and albumin (which is the main protein component of FBS) has been reported to show a considerable affinity by $\mathrm{TiO}_{2} \mathrm{NP}[33,47]$.

\subsection{Image Analysis}

3.3.1. Morphometric Parameters. TEM micrographs of the agglomerates of spheres, E171, and belts $\mathrm{TiO}_{2} \mathrm{NP}$ formed 


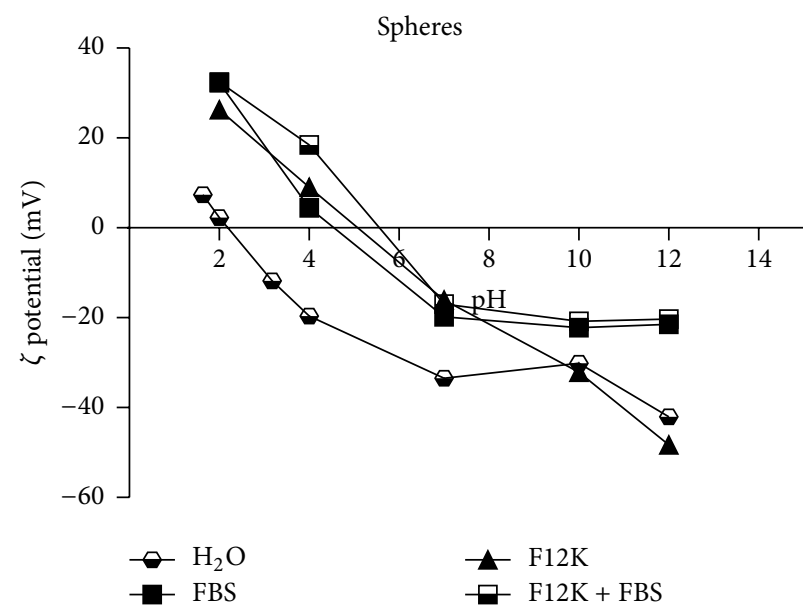

(a)

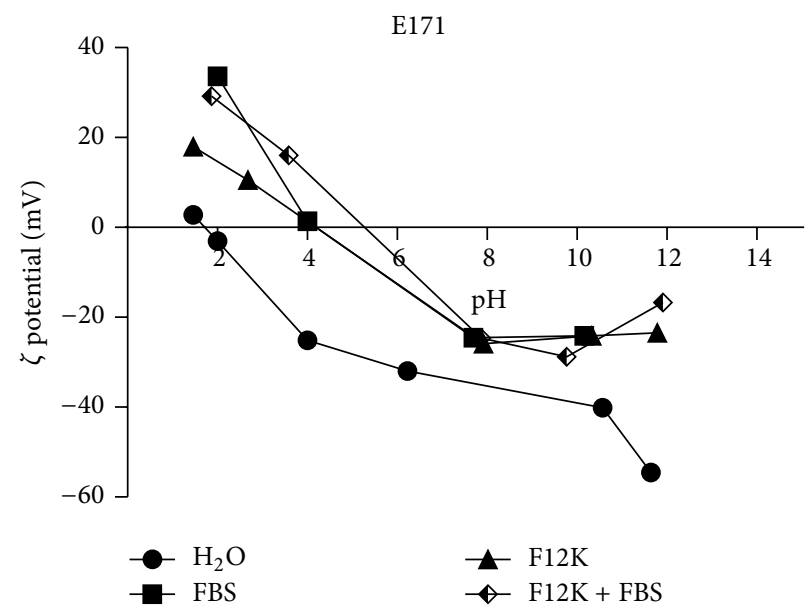

(b)

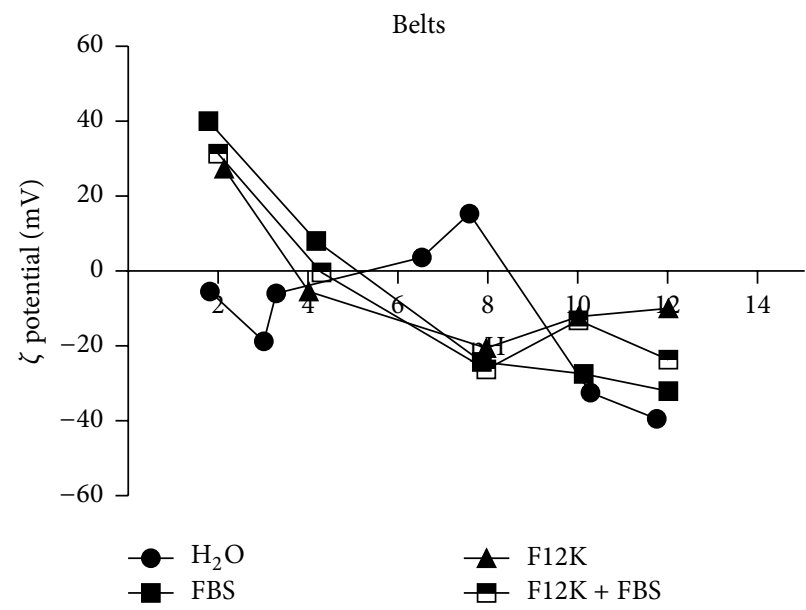

(c)

Figure 4: Titration $\zeta$ curves for each type of $\mathrm{TiO}_{2} \mathrm{NP}$ (a) spheres, (b) E171 NP, and (c) belts, in each medium used $\left(\mathrm{H}_{2} \mathrm{O}, \mathrm{FBS}, \mathrm{F} 12 \mathrm{~K}\right.$, and F12K + FBS). The pHiep (isoelectric point) in water solutions were around 2 in the three cases, (a) the pHiep for spheres suspended in media were around $\mathrm{pH}$ 5-6, (b) the pHiep for E171 suspended in all media (except water) were around $\mathrm{pH}$ 4, and (c) the pHiep for belts suspended in all media (except water) were around 4-5.

from the primary particles in different media are presented in Figure 6; differences in the morphology of the agglomerates in each medium can be qualitatively appreciated which influenced their physiological action [21]. Changes of size with time were typical for all systems and formation of stripes was evident for $\mathrm{TiO}_{2}$ in the form of belts. It is noteworthy that obtained shapes were markedly different from those of the primary particles (Figure 1). 2D images obtained by using TEM and SEM showed snowflakes morphology was observed for agglomerates of spheres dispersed in water that may indicate aggregation controlled by diffusion which has also been reported by different authors $[15,62]$ based on TEM images when working with $\mathrm{TiO}_{2} \mathrm{NP}$ spheres dispersed in water [63].

Projected areas of agglomerates formed in the different media used with the various types of $\mathrm{TiO}_{2} \mathrm{NP}$ are shown in Figure 7. Spheres in F12K media had the largest projected areas of agglomerates while particles dispersed in F12K + FBS had the smallest ones which may make their internalization difficult. This would be more evident when they are dispersed in F12K + FBS media. Areas of agglomerates had the tendency to increase with time and presented approximately the same projected areas at $1440 \mathrm{~min}$ of incubation. Perimeters of the agglomerates formed in the four different media are presented in Figure 7. All systems had the same already mentioned tendency to increase the projected areas and also reached a maximum value at $1440 \mathrm{~min}$ (Figure 7). This was due to the direct relationship existing between these two parameters [47].

Values of the circularity $(\mathrm{Ci})$ of the agglomerates formed in the different media are shown in Figure 7. A significant difference $(p<0.05)$ was found in the $\mathrm{Ci}$ of the agglomerates of spheres in FBS and $\mathrm{H}_{2} \mathrm{O}$, but there were not significant differences in this parameter for the agglomerates formed by E171 NP and belts in the same media or for the agglomerates formed for the same NP in F12K and in F12K + FBS. It was observed that the lowest value of $\mathrm{Ci}$ was obtained for the agglomerates of spheres in $\mathrm{H}_{2} \mathrm{O}$ which may have been formed 
Spheres
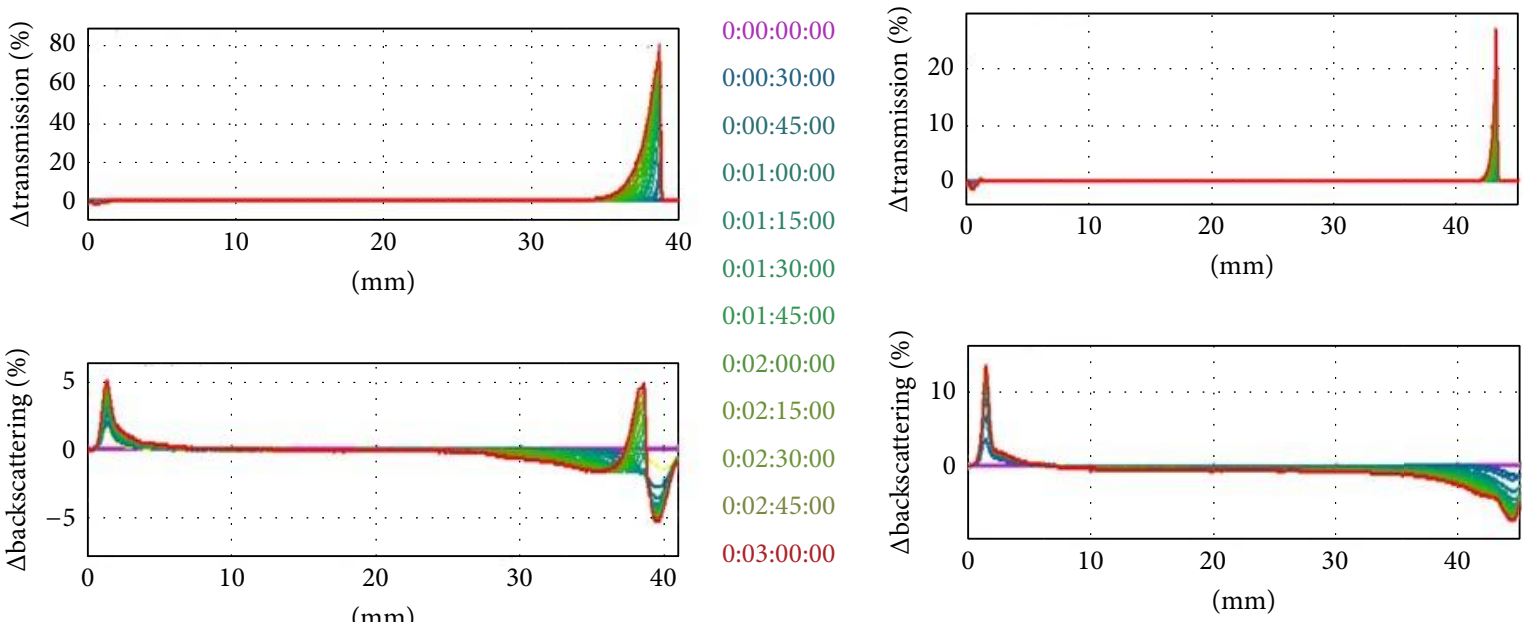

0:00:00:00

0:00:30:00

0:00:45:00

0:01:00:00

0:01:15:00

0:01:30:00

0:01:45:00
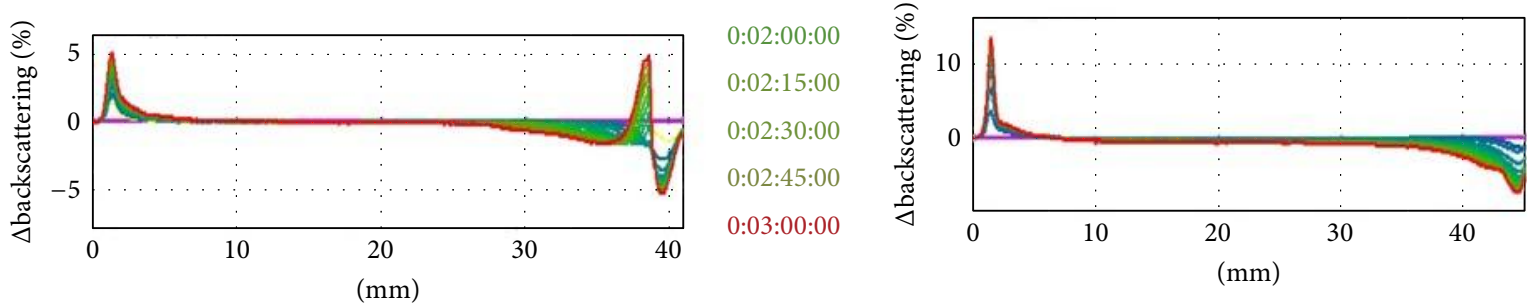

0:02:00:00

0:02:15:00

0:02:30:00

0:02:45:00

0:03:00:00

(a)

(b)

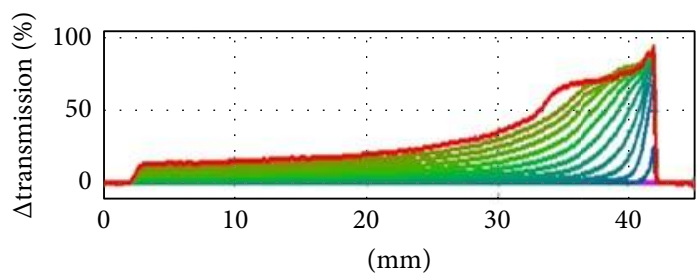

0:00:00:00
0:00:30:00
0:00:45:00
0:01:00:00
0:01:15:00
0:01:30:00

0:01:45:00

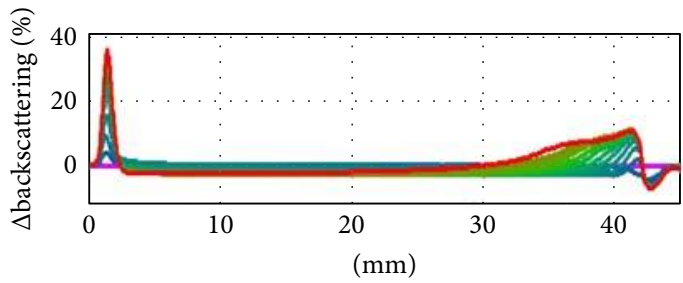

0:02:00:00

0:02:15:00

0:02:30:00

0:02:45:00

0:03:00:00

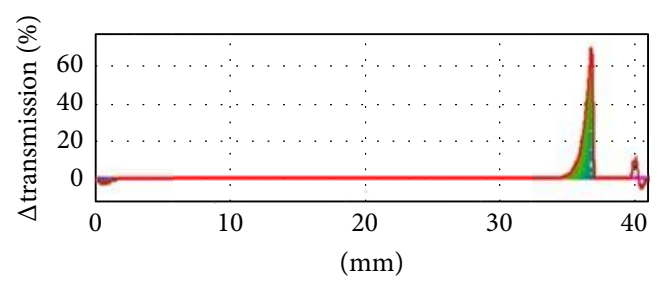

0:00:00:00

0:00:30:00

0:00:45:00

0:01:00:00

0:01:15:00

0:01:30:00

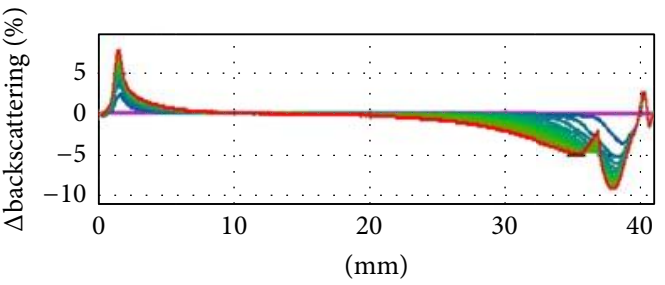

0:01:45:00

0:02:00:00

0:02:15:00

0:02:30:00

0:02:45:00

0:03:00:00

(c)

(d)

E171
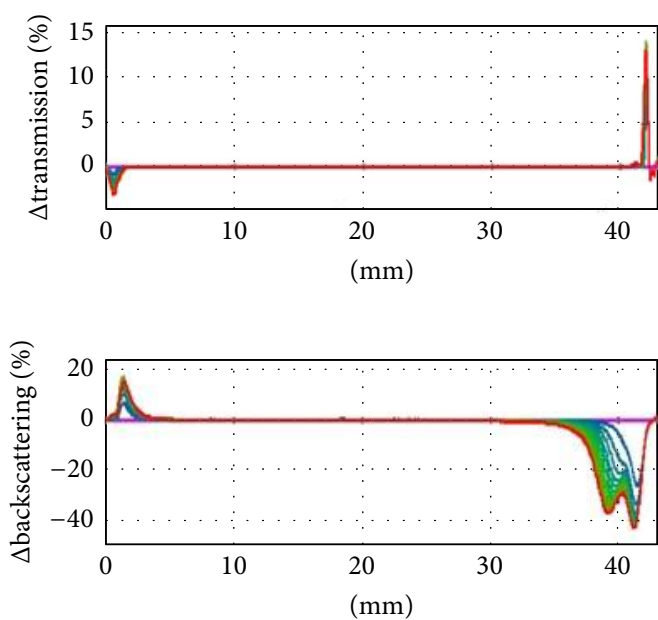

(a)
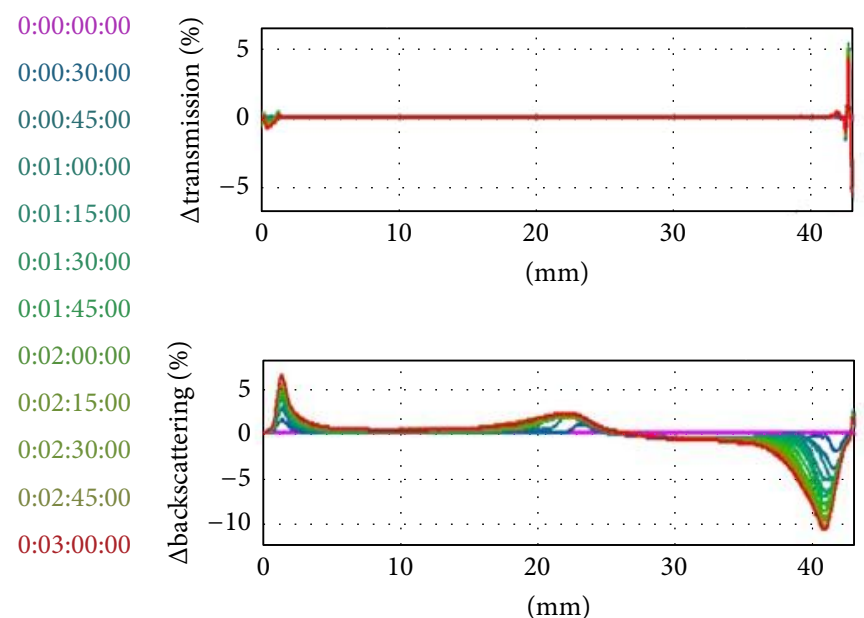

(b)
0:00:00:00

0:00:30:00

0:00:45:00

0:01:00:00

0:01:15:00

0:01:30:00

0:01:45:00

0:02:00:00

0:02:15:00

0:02:30:00

0:02:45:00

0:03:00:00

Figure 5: Continued. 

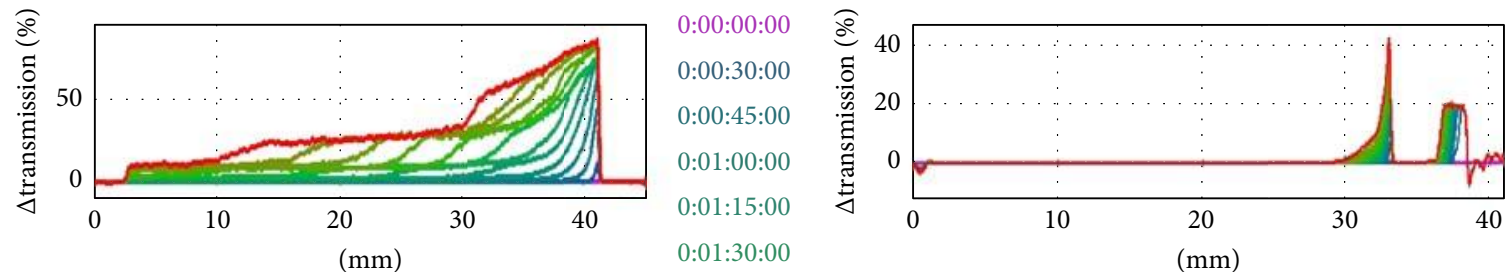

0:00:00:00

0:00:30:00

0:00:45:00

0:01:00:00

0:01:15:00

$0: 01: 45: 00$

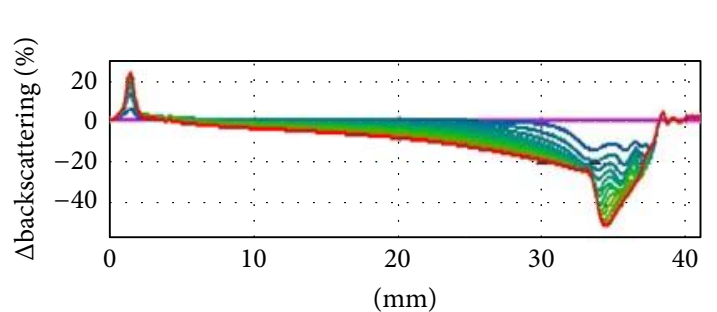

0:01:30:00

0:01:45:00

0:02:00:00

0:02:15:00

0:02:30:00

0:02:45:00

0:02:45:0

0:03:00:00

$(\mathrm{mm})$

(c)

(d)

Belts

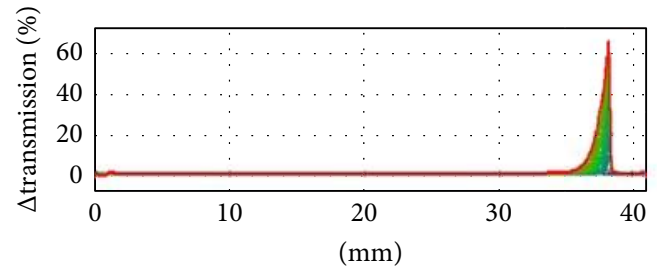

$0: 00: 00: 00$
$0: 00: 30: 00$
$0: 00: 45: 00$
$0: 01: 00: 00$
$0: 01: 15: 00$
$0: 01: 30: 00$

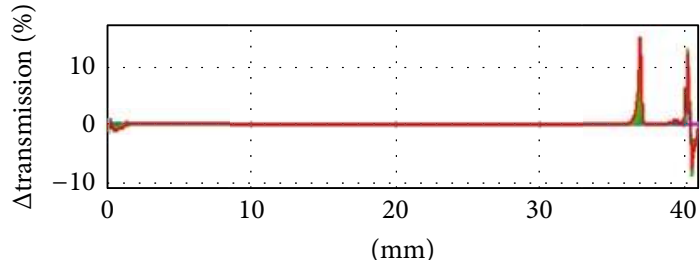

0:00:00:00

0:00:30:00

0:00:45:00

0:01:00:00

0:01:15:00

0:01:30:00

0:01:45:00

0:01:45:00

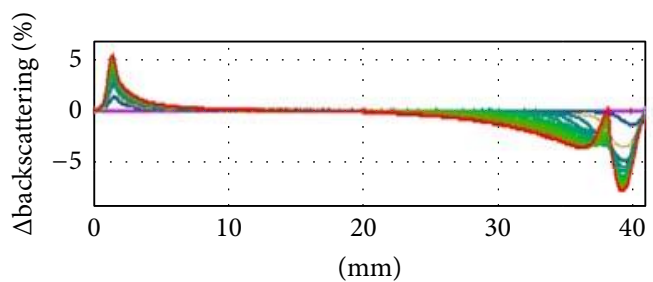

0:02:00:00

0:02:15:00

0:02:30:00

0:02:45:00

0:03:00:00

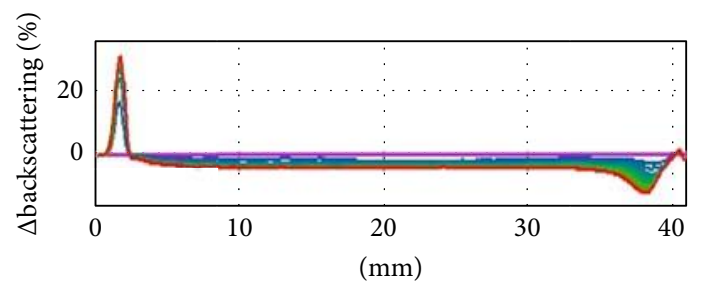

0:02:00:00

0:02:15:00

0:02:30:00

0:02:45:00

0:03:00:00

(a)

(b)

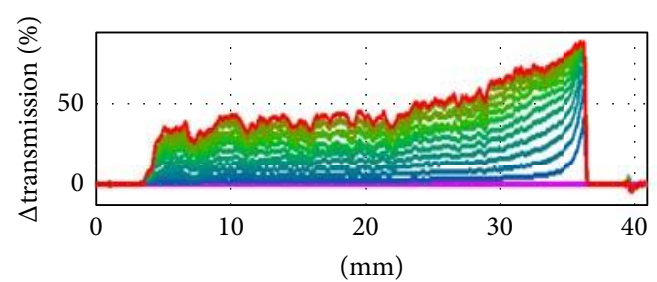

0:00:00:00
0:00:30:00
0:00:45:00
0:01:00:00
0:01:15:00
0:01:30:00

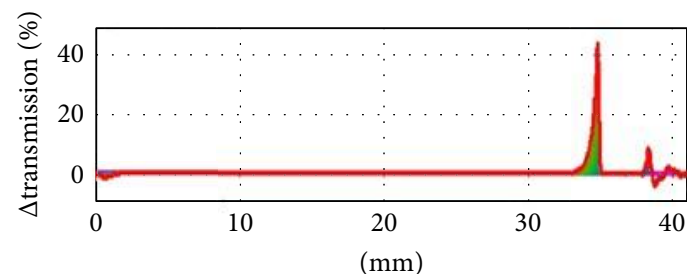

0:00:00:00

0:00:30:00

0:00:45:00

0:01:00:00

0:01:15:00

0:01:30:00

0:01:45:00

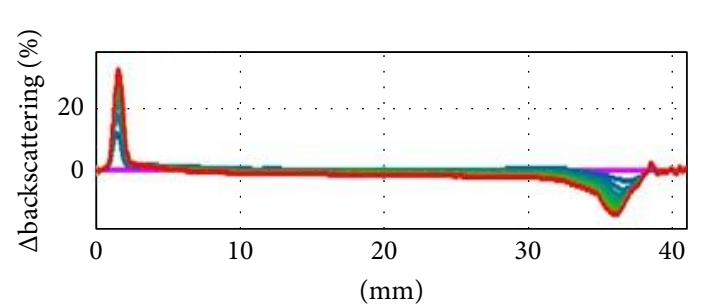

0:01:45:00

0:02:00:00

0:02:15:00

0:02:30:00

0:02:45:00

0:03:00:00

0:02:45:00

0:03:00:00

(mm)

(d)

FIGURE 5: Backscattering and transmission profiles by Turbiscan Lab stability analysis measured during 30 with 15 min of intervals; spheres, E171, and belts suspended in (a) $\mathrm{H}_{2} \mathrm{O}$, (b) FBS, (c) F12K, and (d) F12K + FBS. 
Spheres

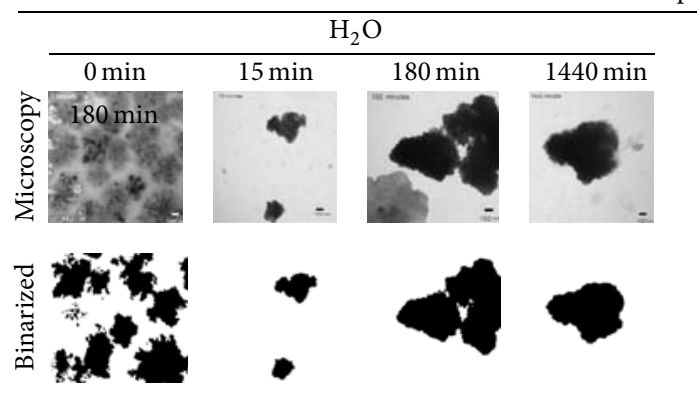

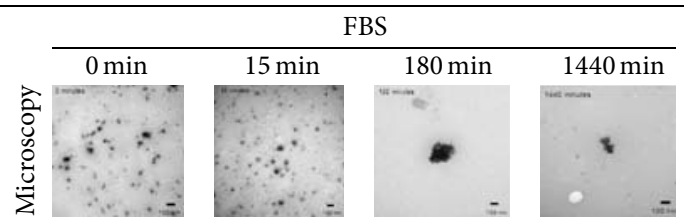

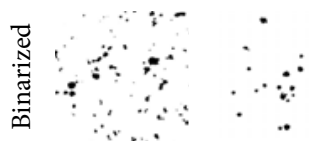

胥

8

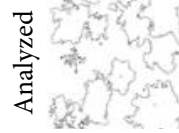

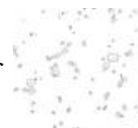

F12K
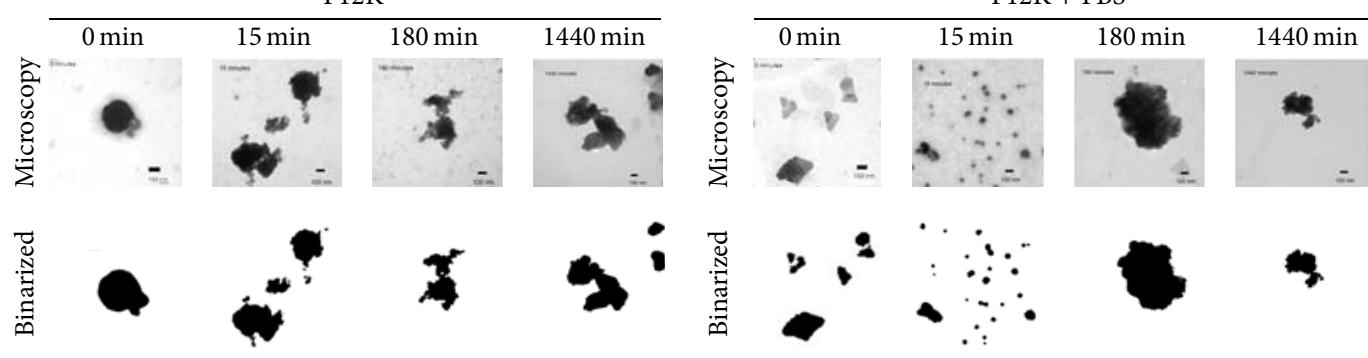

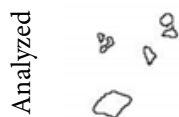

䒿

E171

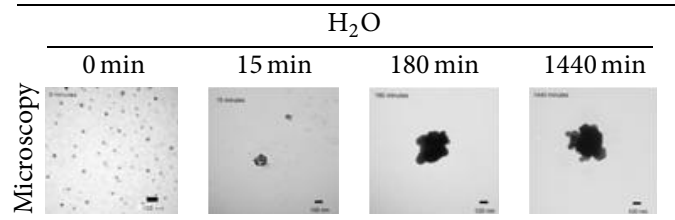

\begin{tabular}{c}
\multicolumn{4}{c}{ FBS } \\
\cline { 2 - 4 } \\
\hline
\end{tabular}
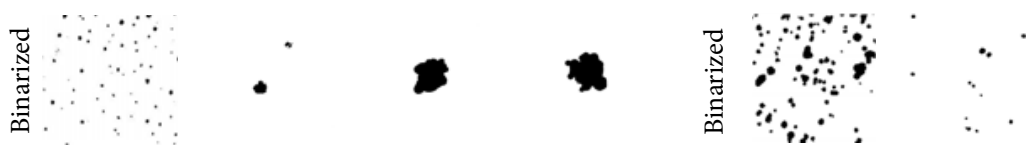

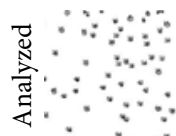
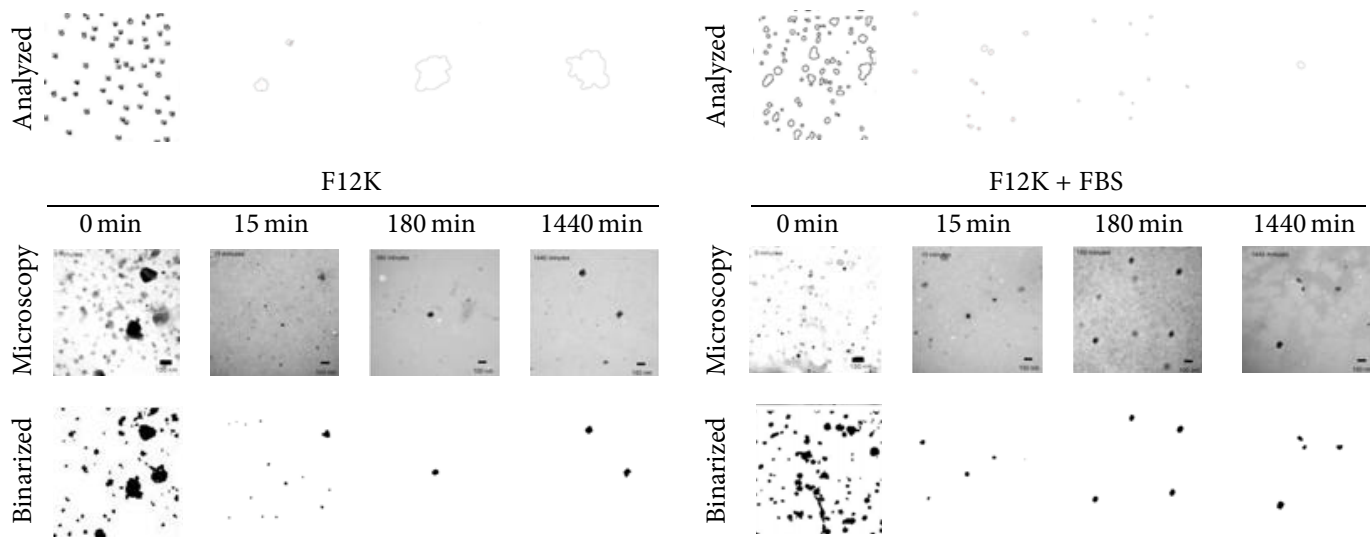

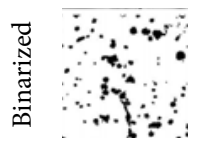

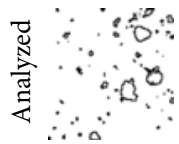

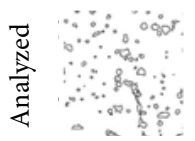

FIgURe 6: Continued. 


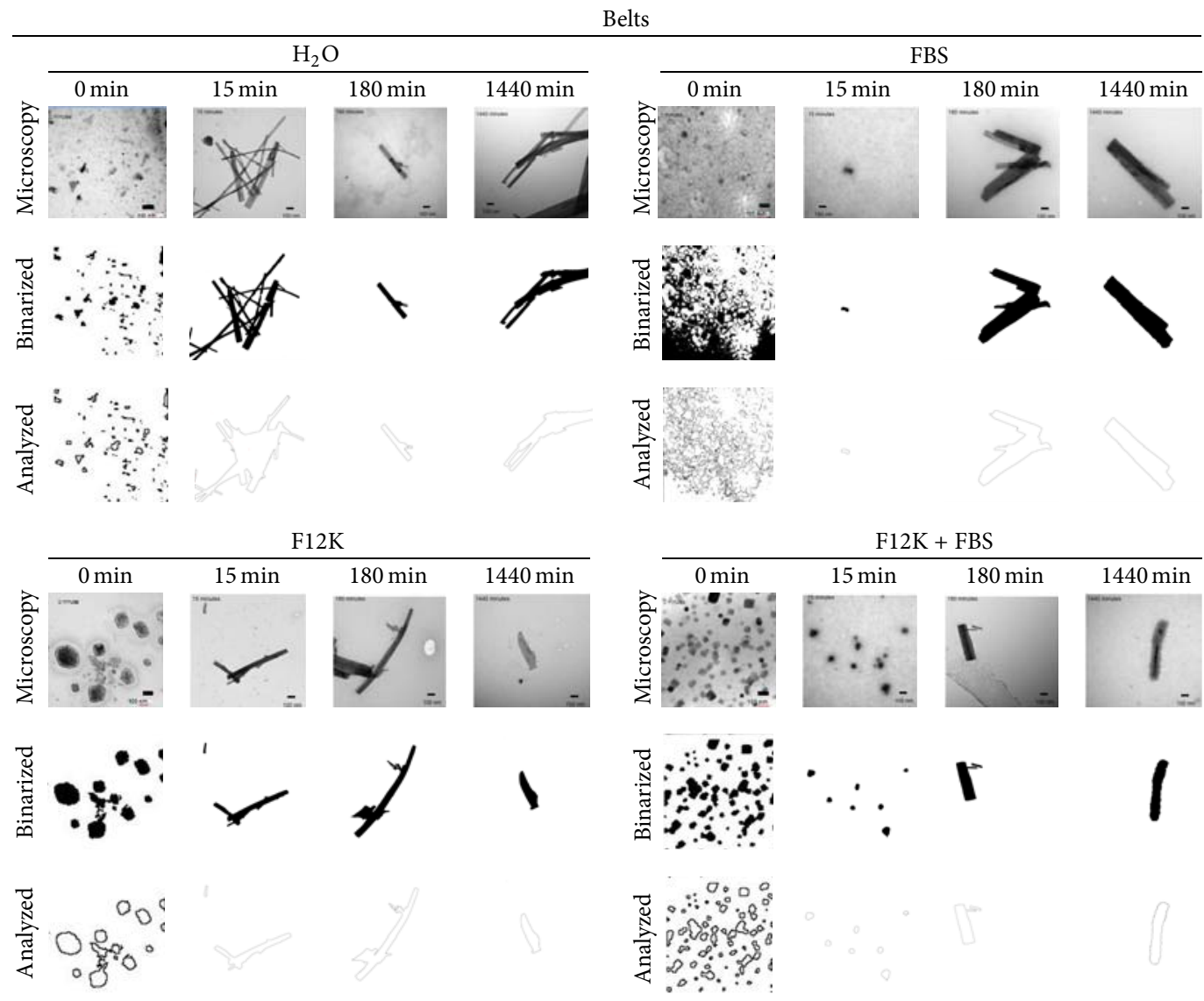

FIGURE 6: TEM micrographs of agglomerates of $\mathrm{TiO}_{2} \mathrm{NP}$ of different shapes (spheres, E171, and belts) in various media in a sequence time, binarized and analyzed by DIA.

by agglomeration limited by diffusion [62] and which had a characteristic snowflake structure with $\mathrm{Ci}$ values around 0.5 and had been formed by individual particles with an average size of $413 \mathrm{~nm}$ (Figure 7). Ci of all systems remained practically unchanged for all systems (except for belts) with time for $1440 \mathrm{~min}$ (Figure 7), which indicated that increments in size did not affect their morphology. $\mathrm{Ci}$ of belts had a tendency to decrease with time (Figure 7), due to the abovementioned (see Figure 6) tendency to aggregate forming stripes (belts) [47].

Values of Fe of the agglomerates formed in $\mathrm{H}_{2} \mathrm{O}, \mathrm{SFB}$, and F12K + SFB are presented in Figure 7. Values of HD were 1050 times larger than those evaluated by DIA; this was due to the fact that $\mathrm{HD}$ considers the size of the electrical double layer formed around NP [62]. Largest Fe values were found in the NP suspended in FBS and F12K; however, when the NP were suspended in the F12K + FBS system, these values decreased by more than $50 \%$ in the case of spheres and by $20 \%$ for E171. The smallest agglomerates found by DLS $(55.8 \mathrm{~nm})$ and $\mathrm{Fe}(\approx 10 \mathrm{~nm})$ by TEM were found for belts suspended in FBS which may be due to the fact that FBS is a good dispersant causing agglomerates in these media to be smaller [15]. Fe showed approximately the same tendency to increase than area and $\mathrm{Ci}$ and reached a maximum value at $1440 \mathrm{~min}$ as shown in Figure 7.
The aspect ratios (AR) of the agglomerates formed in the four media are presented in Figure 7. No differences were found in this parameter for agglomerates formed with spheres and belts although differences $(p<0.05)$ were found between agglomerates formed in E171, $\mathrm{H}_{2} \mathrm{O}$, FBS, and F12K media. No differences were found $(p>0.05)$ between agglomerates formed in F12K + FBS. When agglomerates have rough surfaces, as in the case of belts in $\mathrm{H}_{2} \mathrm{O}, \mathrm{Ci}$, and $\mathrm{AR}$ values tended to be large since particles have a shape closer to a sphere but present borders, dents, and deformations that provoked the higher longest axis found.

3.3.2. Fractal Dimension. Roughness of the contours of agglomerates was evaluated by their fractal dimension (FD), as presented in Figure 7. Agglomerates presented values of FD values ranging within 1.3-1.7. High FD values (regardless of the size of the primary constituent particles) have been associated with irregular structures and with higher surface areas as compared to those having low FD [64]. Also, the FD of the agglomerates of spheres dispersed in $\mathrm{H}_{2} \mathrm{O}$ (which had snowflake-morphology) was larger than the FD value of the agglomerates of E171 and belts dispersed in the same media and which were also associated with the smallest $\mathrm{Ci}$ values and highest AR values. 
Spheres
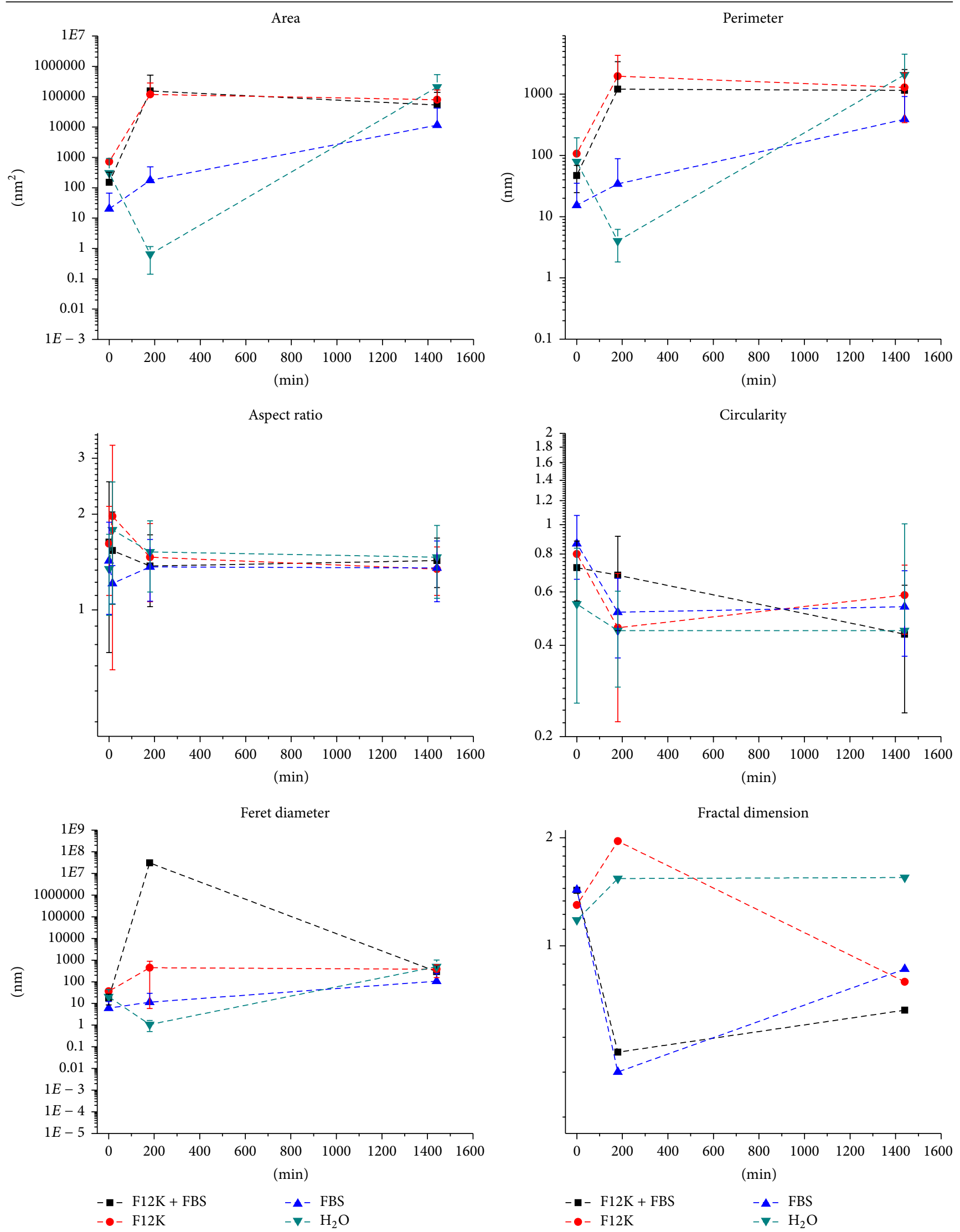

FIGURE 7: Continued. 
E171
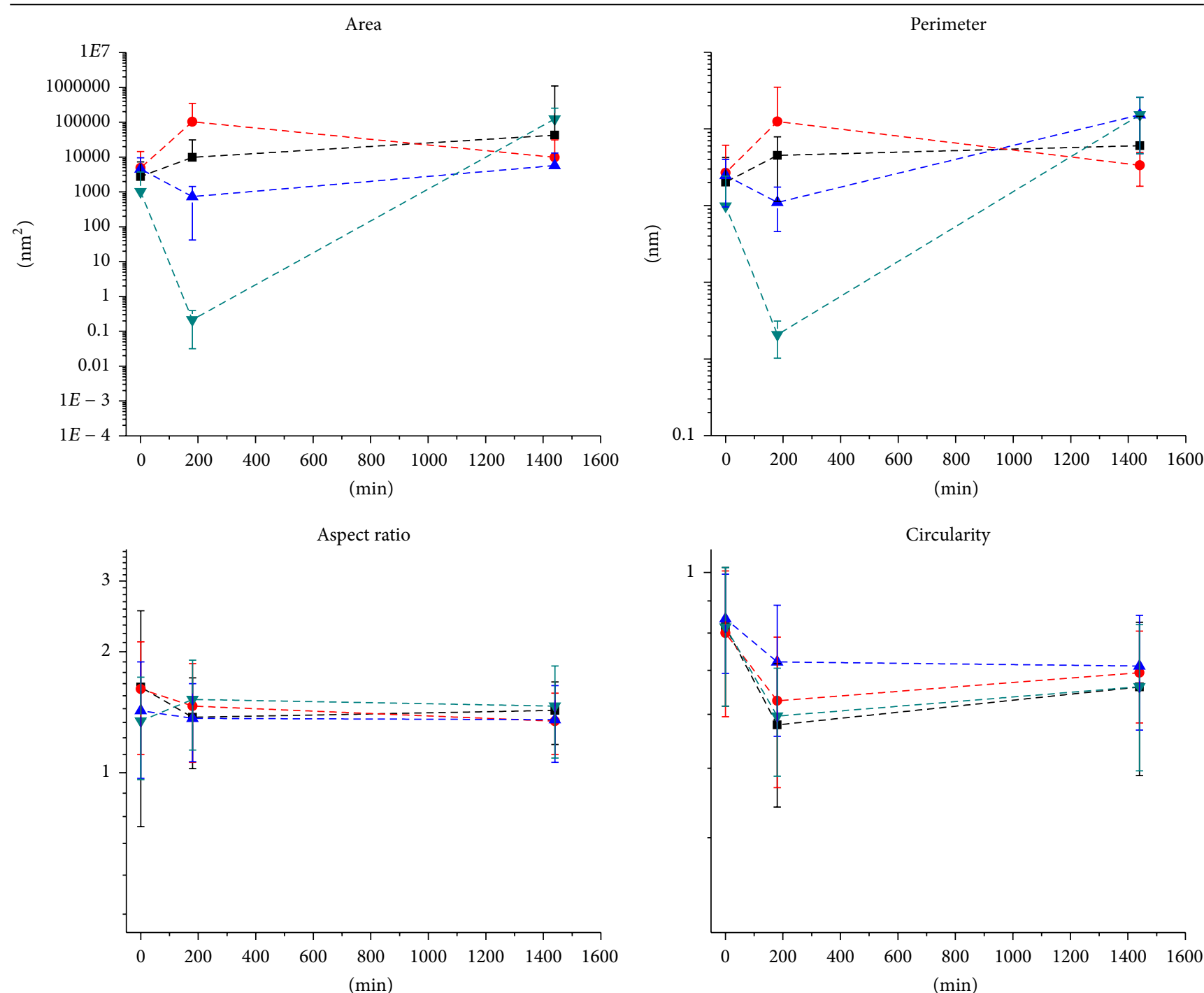

Circularity
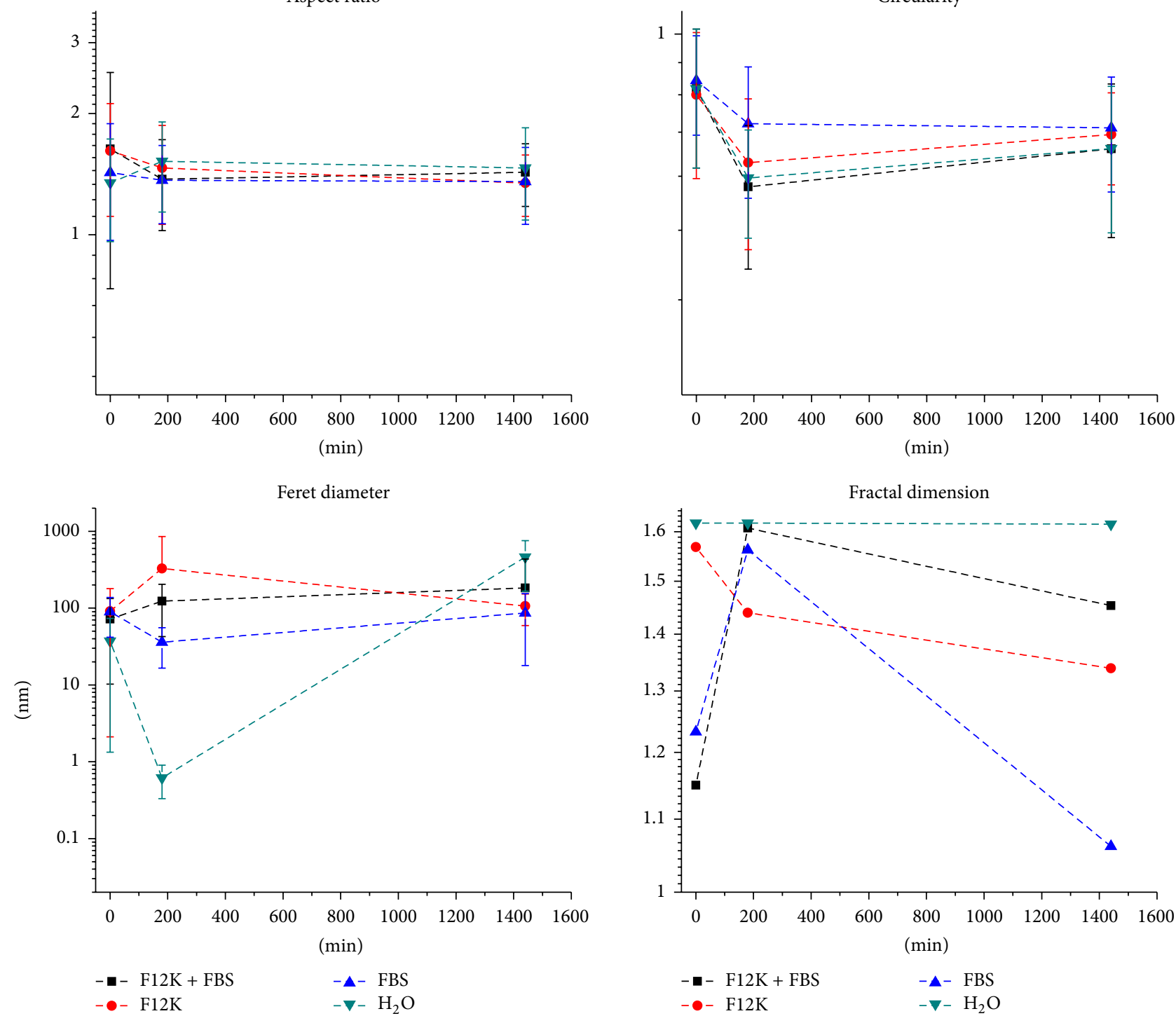

FIgURE 7: Continued. 
Belts
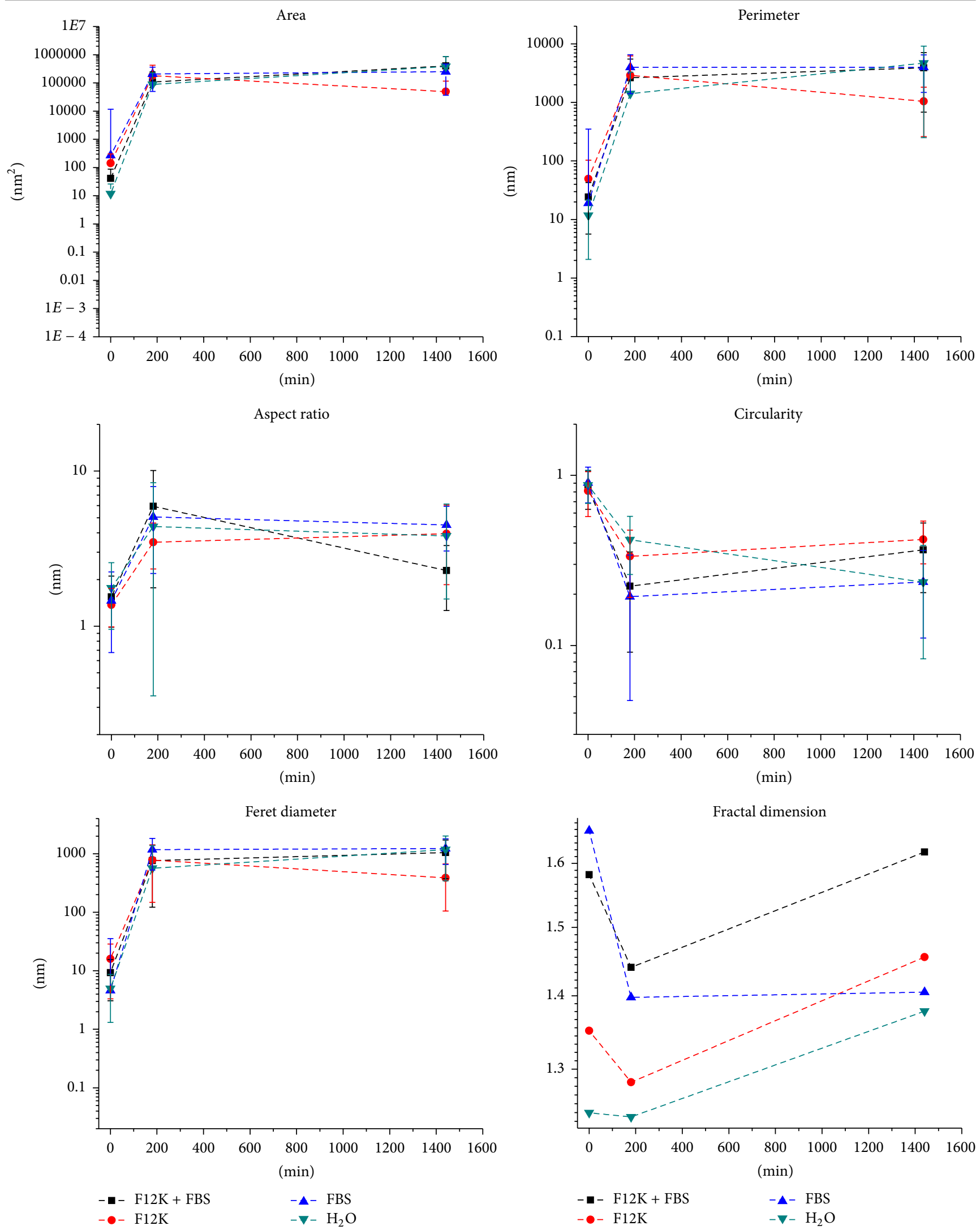

FIgURE 7: Parameters derived from the image analysis of the agglomerates formed for $\mathrm{TiO}_{2} \mathrm{NP}$ of different shapes in different media: area, perimeter, circularity, Feret's diameter, aspect ratio, and fractal dimension. 
TABLe 1: Pearson's coefficients between $A_{\mathrm{F}}$ and $\mathrm{Fe}^{\mathrm{FD}}$.

\begin{tabular}{lcccc}
\hline & $\mathrm{H}_{2} \mathrm{O}$ & FBS & F12K & F12K + FBS \\
\hline Spheres & 0.9908 & 0.9055 & 0.9979 & 0.98177 \\
E171 & 0.8696 & 0.9477 & 0.9918 & 0.7750 \\
Belts & 0.9593 & - & 0.9864 & 0.9625 \\
\hline
\end{tabular}

There were significant differences $(p<0.05)$ for the FD values of E171 agglomerates suspended in the different media. In addition, the FD values of E171 agglomerates dispersed in F12K cell culture media were smaller than those corresponding to agglomerates of spheres and belts in the same media which may be due to the amorphous geometry structure of the E171 primary nanoparticles that causes stereoscopic effects and high surface roughness.

The highest FD values found corresponded to agglomerates of spheres and belts dispersed in F12K and E171 dispersed in FBS as well as for spheres in $\mathrm{H}_{2} \mathrm{O}$. Consequently these agglomerates had more spaces in their structures (Figure 7) which made them more accessible to external compounds. FD for all systems showed a tendency to fluctuate with time of incubation. Dispersions in water presented the lowest fluctuations of FD values; dispersion of spheres had a tendency to increase and then to decrease and, in particular, dispersions in FBS had the biggest decrement of FD whereas FD values for dispersions of E171 in water and F12K increased and then decreased while dispersions in FBS and F12K + FBS decreased and then increased their FD. Belts in all media had approximately similar tendencies to decrease and then to increase. In all studied systems, agglomeration was carried out by aggregation and disaggregation of proteins, amino acids, and salts which interact in a complex and different way with $\mathrm{TiO}_{2}$ in each system making the evaluation of irregularity of agglomeration (in the form of a FD) necessary when effects of $\mathrm{TiO}_{2} \mathrm{NP}$ on biological effects are investigated. Furthermore, the agglomerates attached to different compounds in the media might change their dynamics in the fluids before, during, and after cell internalization [14, 64]. All $\mathrm{TiO}_{2}$ agglomerates followed a power law given by (1) in Section 2.5. High Pearson's correlation coefficients (Table 1) were associated with increased values of Fractal area of agglomerates evaluated by DIA which means that the filling of the area of agglomerates followed a fractional (fractal) exponent $<2$ (values of the fractal dimension at the initial times depicted in Figure 7) with reported Feret perimeters. Similar observations were reported in the filling of ampullas (structures related to capsaicin production in chili peppers) [52].

Although TEM micrographs of $\mathrm{TiO}_{2} \mathrm{NP}$ agglomerates, as well as their size and $\zeta$ values, have been published in previous works [15], quantitative descriptors of their morphology have been scarcely reported. Differences in morphology and electric charge-related characteristics such as $\zeta$ may cause marked differences in their biological effects when NP interacts in the environments with living organisms. For example, some authors microencapsulated lung-directed delivery proteins in the form of chitosan NP [54] having Fe of $430 \mathrm{~nm}$ and $\zeta$ of $-44 \mathrm{mV}$. In the cited work, media compounds seem to form a protein corona around $\mathrm{TiO}_{2} \mathrm{NP}$ agglomerates that modified its surface charge and morphology. Plasma and albumin are the major components of protein corona and its formation also depends on the affinity of the $\mathrm{TiO}_{2} \mathrm{NP}$ for the components of the media [46]. Nonetheless, little is known on the effect of particle physicochemical properties and the mechanisms of gastrointestinal particle uptake [65]. Size, type, composition, and morphology of the polymers have been studied for pharmacological purposes directed to absorption of micro or nanocapsules across mucosal barriers [66]. The exploitation of particulate carrier systems for the delivery of peptides and other hydrophilic macromolecules remains a challenging task due, precisely, to morphological and physiological absorption barriers in different mucosa and in the gastrointestinal tract. Findings related to size, morphology, and electric charge in different media may be useful for further in vivo and in vitro studies on the relationships between micro/nanostructures and possible functional consequences of agglomerates of various types of $\mathrm{TiO}_{2} \mathrm{NP}$ in different media and environments. Interactions between components of media and the NP influenced the affinity and adhesion of such components on the NP thus promoting or preventing the formation of agglomerates with different morphologies, sizes, and $\zeta$. A number of works have been published in which the importance of evaluating the interactions of various media-NP such as fetal bovine serum- $\mathrm{TiO}_{2}$ [53], $\mathrm{TiO}_{2}$-cell culture media [23], blood [67], and bronchioalveolar fluids [14] is stressed that form layers of proteins around NP named protein corona [54]. A number of studies have been carried out regarding $\mathrm{TiO}_{2}$ effects in different in vivo and in vitro systems and it is noteworthy that different morphologies, sizes, and charge (as $\zeta$ ) of the $\mathrm{TiO}_{2}$ agglomerates and primary particles cause a number of biological changes when they are internalized into cells. Also $\mathrm{TiO}_{2}$ has been reported to influence such changes which were also dose-response. Detailed information of such effects is presented in Table 2. It is noteworthy that nevertheless shape, size, and charge of primary $\mathrm{TiO}_{2} \mathrm{NP}$ are, in general, reported but no evaluation of size-morphometry of agglomerates has been found in relation to biological effects evaluated, and a lack of data in this regard is important. A quantitative study of morphometry, associated with corresponding sizes is, in general, missing although it has been recognized as important towards biological effects by different authors [54, 68-70]. It is also important to highlight that titration $\zeta$ curves such as those evaluated in our work are, in general, scarce in the literature in spite of the fact that changes in $\mathrm{pH}$ are frequently associated with oxidative stress processes.

The results from this work help to understand the complex NP geometry-size-stability relationships when performing toxicology and environmental studies as well as help in supporting forthcoming regulations regarding the usage of $\mathrm{TiO}_{2}$ NP.

\section{Conclusions}

Different manners of agglomeration were observed for each type of $\mathrm{TiO}_{2} \mathrm{NP}$ in the different media. Sizes of agglomerates measured by DLS were larger than those evaluated DIA by $10-$ 50 times due to the electrically charged zone formed around 


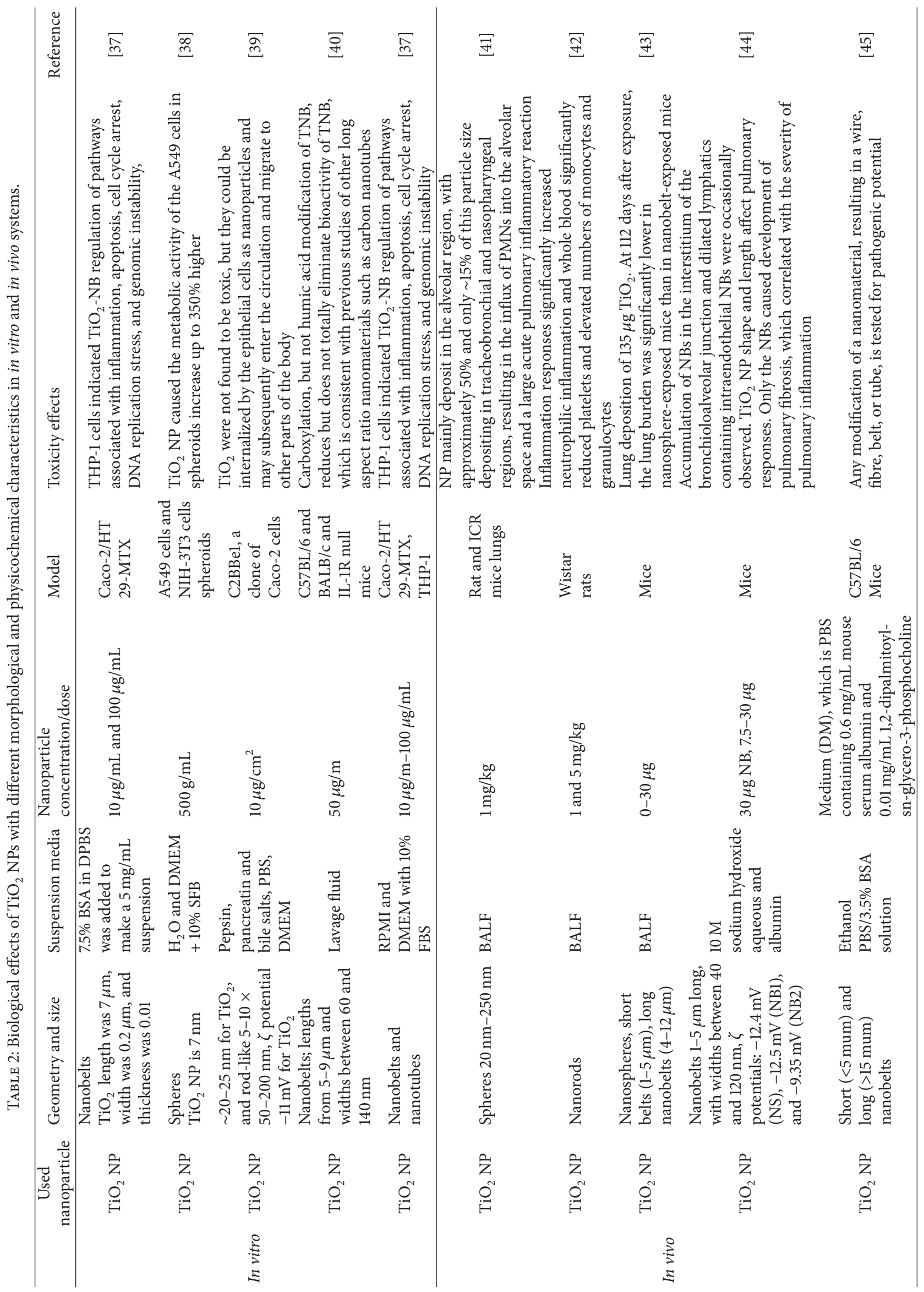


the particles and whose thickness was included in the HD reported by DLS. Fe and AR correlated for E171 NP, and it was possible to differentiate between E171 agglomerates. Aspect ratio was a better descriptor of the shape of agglomerates than $\mathrm{Ci}$ since it allowed differentiating between particles. All determined areas of $\mathrm{TiO}_{2} \mathrm{NP}$ agglomerates followed a power law relationship with $\mathrm{Fe}^{\mathrm{FD}}$. $\zeta$ values found for $\mathrm{TiO}_{2} \mathrm{NP}$ suspensions (except suspensions in water) at physiological $\mathrm{pH}$ (7.4) were as follows: E171 < belts < spheres. Size, shape, and stability with time are distinctive characteristics of each NP media system so that this type of studies should be performed for the design of both in vivo and in vitro experiments. The results from this work can also help to understand the complex NP geometry-size-stability relationships when performing in vivo and in vitro environmentaltoxicity works and would help in understanding mechanisms by which morphometry, stability with time, and $\zeta$ of $\mathrm{TiO}_{2} \mathrm{NP}$ determine if these NP will be carried by physiological fluids or accumulated in body tissues and will also help in supporting usage of $\mathrm{TiO}_{2} \mathrm{NP}$.

\section{Highlights}

Size, morphology, and $\zeta$ of $\mathrm{TiO}_{2} \mathrm{NP}$ agglomerates in media used in toxicology were determined.

Highest values of fractal dimension (FD) were found for E171 and belts agglomerates.

All dispersions had $\zeta$ values around $-30 \mathrm{mV}$ at physiological pH (7.4).

Dispersions of $\mathrm{TiO}_{2} \mathrm{NP}$ in water and in FBS showed their maximum stability by Turbiscan Lab analysis.

Results help in understanding NP geometry-sizestability in environmental toxicology studies.

\section{Conflict of Interests}

The authors report no conflict of interests.

\section{Acknowledgments}

Authors Verónica Freyre-Fonseca and Estefany I. MedinaReyes thank CONACyT for financial support in the form of Ph.D. Study Grants nos. 202805 and 579881, respectively. The authors thank Dr. Jaime Vernon-Carter and Dr. María Eugenia Jaramillo-Flores for support with DLS experiments, Dr. Mayahuel Ortega for their technical help in image acquisition, Ms. Julieta Villalobos, and Dr. Evangelina García Armenta for support with image analysis. The authors acknowledge financial support from CONACyT, Mexico, through Research Grants 166727 and 118088, as well as IPNSIP, Mexico.

\section{References}

[1] A. Weir, P. Westerhoff, L. Fabricius, K. Hristovski, and N. von Goetz, "Titanium dioxide nanoparticles in food and personal care products," Environmental Science and Technology, vol. 46, no. 4, pp. 2242-2250, 2012.
[2] B. B. Luna Sánchez, E. Zermeno-Resendiz, E. Moctezuma, R. E. Contreras-Bermúdez, E. Leyva, and M. A. López-Barragán, "Photodegradation of omeprazol in aqueous solution using $\mathrm{TiO}_{2}$ as catalyst," Revista Mexicana de Ingeniería Química, vol. 12, no. 1, pp. 85-95, 2013.

[3] J. Vergara-Sánchez, J. P. Pérez-Orozco, R. Suárez-Parra, and I. Hernández-Pérez, "Degradation of reactive red 120 azo dye in aqueous solutions using homogeneous/heterogeneous iron systems," Revista Mexicana de Ingeniería Química, vol. 11, no. 1, pp. 121-131, 2012.

[4] F. Sauvage, C. Davoisne, L. Philippe, and J. Elias, "Structural and optical characterization of electrodeposited CdSe in mesoporous anatase $\mathrm{TiO}_{2}$ for regenerative quantum-dot-sensitized solar cells," Nanotechnology, vol. 23, no. 39, pp. 395-401, 2012.

[5] B. D. Johnston, T. M. Scown, J. Moger et al., "Bioavailability of nanoscale metal oxides $\mathrm{TiO}_{2}, \mathrm{CeO}_{2}$, and $\mathrm{ZnO}$ to fish," Environmental Science and Technology, vol. 44, no. 3, pp. 11441151, 2010.

[6] K. Bhattacharya, M. Davoren, J. Boertz, R. P. F. Schins, E. Hoffmann, and E. Dopp, "Titanium dioxide nanoparticles induce oxidative stress and DNA-adduct formation but not DNAbreakage in human lung cells," Particle and Fibre Toxicology, vol. 6, article 17, 2009.

[7] N. Li, L. Ma, J. Wang et al., "Interaction between nano-anatase $\mathrm{TiO}_{2}$ and Liver DNA from mice in vivo," Nanoscale Research Letters, vol. 5, no. 1, pp. 108-115, 2010.

[8] D. Sekar, M. L. Falcioni, G. Barucca, and G. Falcioni, "DNA damage and repair following in vitro exposure to two different forms of titanium dioxide nanoparticles on trout erythrocyte," Environmental Toxicology, vol. 29, no. 1, pp. 117-127, 2014.

[9] K. Peters, R. E. Unger, C. J. Kirkpatrick, A. M. Gatti, and E. Monari, "Effects of nano-scaled particles on endothelial cell function in vitro: studies on viability, proliferation and inflammation," Journal of Materials Science: Materials in Medicine, vol. 15, no. 4, pp. 321-325, 2004.

[10] M. C. E. Lomer, R. P. H. Thompson, and J. J. Powell, "Fine and ultrafine particles of the diet: influence on the mucosal immune response and association with crohn's disease," Proceedings of the Nutrition Society, vol. 61, no. 1, pp. 123-130, 2002.

[11] M. Butler, J. J. Boyle, J. J. Powell, R. J. Playford, and S. Ghosh, "Dietary microparticles implicated in Crohn's disease can impair macrophage phagocytic activity and act as adjuvants in the presence of bacterial stimuli," Inflammation Research, vol. 56, no. 9, pp. 353-361, 2007.

[12] M.-H. Cha, T. Rhim, K. H. Kim, A.-S. Jang, Y.-K. Paik, and C.-S. Park, "Proteomic identification of macrophage migrationinhibitory factor upon exposure to $\mathrm{TiO}_{2}$ particles," Molecular and Cellular Proteomics, vol. 6, no. 1, pp. 56-63, 2007.

[13] J. Zhaoy, N. Li, S. Wangy et al., "The mechanism of oxidative damage in the nephrotoxicity of mice caused by nano-anatase $\mathrm{TiO}_{2}$," Journal of Experimental Nanoscience, vol. 5, no. 5, pp. 447-462, 2010.

[14] G. Oberdorster, J. Ferin, and B. E. Lehnert, "Correlation between particle size, in vivo particle persistence, and lung injury," Environmental Health Perspectives, vol. 102, no. 5, pp. 173-179, 1994.

[15] Z. E. Allouni, M. R. Cimpan, P. J. Høl, T. Skodvin, and N. R. Gjerdet, "Agglomeration and sedimentation of $\mathrm{TiO}_{2}$ nanoparticles in cell culture medium," Colloids and Surfaces B: Biointerfaces, vol. 68, no. 1, pp. 83-87, 2009. 
[16] A. E. Nel, L. Mädler, D. Velegol et al., "Understanding biophysicochemical interactions at the nano-bio interface," Nature Materials, vol. 8, no. 7, pp. 543-557, 2009.

[17] R. F. Domingos, M. A. Baalousha, Y. Ju-Nam et al., "Characterizing manufactured nanoparticles in the environment: multimethod determination of particle sizes," Environmental Science and Technology, vol. 43, no. 19, pp. 7277-7284, 2009.

[18] F. Gentile, M. Ferrari, and P. Decuzzi, "The transport of nanoparticles in blood vessels: the effect of vessel permeability and blood rheology," Annals of Biomedical Engineering, vol. 36, no. 2, pp. 254-261, 2008.

[19] R. C. Murdock, L. Braydich-Stolle, A. M. Schrand, J. J. Schlager, and S. M. Hussain, "Characterization of nanomaterial dispersion in solution prior to in vitro exposure using dynamic light scattering technique," Toxicological Sciences, vol. 101, no. 2, pp. 239-253, 2008.

[20] J. A. Champion and S. Mitragotri, "Role of target geometry in phagocytosis," Proceedings of the National Academy of Sciences of the United States of America, vol. 103, no. 13, pp. 4930-4934, 2006.

[21] P. Decuzzi, R. Pasqualini, W. Arap, and M. Ferrari, "Intravascular delivery of particulate systems: does geometry really matter?" Pharmaceutical Research, vol. 26, no. 1, pp. 235-243, 2009.

[22] D. Dutta, S. K. Sundaram, J. G. Teeguarden et al., "Adsorbed proteins influence the biological activity and molecular targeting of nanomaterials," Toxicological Sciences, vol. 100, no. 1, pp. 303$315,2007$.

[23] Z. Ji, X. Jin, S. George et al., "Dispersion and stability optimization of $\mathrm{TiO}_{2}$ nanoparticles in cell culture media," Environmental Science and Technology, vol. 44, no. 19, pp. 7309-7314, 2010.

[24] A. J. Kodagali and S. Balaji, "Computer vision and image analysis based techniques for automatic characterization of fruits-a review," International Journal of Computer Applications, vol. 50, no. 6, pp. 6-12, 2012.

[25] C. Y. Kuo, J. D. Frost, J. S. Lai, and L. B. Wang, “Three dimensional image analysis of aggregate particles from orthogonal projections," Transportation Research Record, vol. 1526, no. 1, pp. 98-103, 1996.

[26] C. R. Thomas and G. C. Paul, "Applications of image analysis in cell technology," Current Opinion in Biotechnology, vol. 7, no. 1, pp. 35-45, 1996.

[27] M. Vučak, M. N. Pons, J. Perić, and H. Vivier, "Effect of precipitation conditions on the morphology of calcium carbonate: quantification of crystal shapes using image analysis," Powder Technology, vol. 97, no. 1, pp. 1-5, 1998.

[28] S. Almeida-Prieto, J. Blanco-Méndez, and F. J. Otero-Espinar, "Microscopic image analysis techniques for the morphological characterization of pharmaceutical particles: influence of the software, and the factor algorithms used in the shape factor estimation," European Journal of Pharmaceutics and Biopharmaceutics, vol. 67, no. 3, pp. 766-776, 2007.

[29] A. Cameirão, R. David, F. Espitalier, and F. Gruy, "Effect of precipitation conditions on the morphology of strontium molybdate agglomerates," Journal of Crystal Growth, vol. 310, no. 18, pp. 4152-4162, 2008.

[30] R. Wild, M. Dhanabal, T. A. Olson, and S. Ramakrishnan, "Inhibition of angiogenesis and tumour growth by VEGF121toxin conjugate: differential effect on proliferating endothelial cells," British Journal of Cancer, vol. 83, no. 8, pp. 1077-1083, 2000 .
[31] C. Y. Kuo, J. D. Frost, J. S. Lai, and L. B. Wang, "Threedimensional image analysis of aggregate particles from orthogonal projections," Transportation Research Record: Journal of the Transportation Research Board, vol. 1526, 1996.

[32] P. M. Kieran, D. M. Malone, and P. F. MacLoughlin, "Effects of hydrodynamic and interfacial forces on plant cell suspension systems," in Influence of Stress on Cell Growth and Product Formation, vol. 67 of Advances in Biochemical Engineering/Biotechnology, pp. 139-177, Springer, Berlin, Germany, 2000.

[33] F. Pedreschi, J. León, D. Mery, and P. Moyano, "Development of a computer vision system to measure the color of potato chips," Food Research International, vol. 39, no. 10, pp. 1092-1098, 2006.

[34] M. Lundqvist, J. Stigler, G. Elia, I. Lynch, T. Cedervall, and K. A. Dawson, "Nanoparticle size and surface properties determine the protein corona with possible implications for biological impacts," Proceedings of the National Academy of Sciences of the United States of America, vol. 105, no. 38, pp. 14265-14270, 2008.

[35] C. Celia, E. Trapasso, D. Cosco, D. Paolino, and M. Fresta, "Turbiscan Lab Expert analysis of the stability of ethosomes and ultradeformable liposomes containing a bilayer fluidizing agent," Colloids and Surfaces B: Biointerfaces, vol. 72, no. 1, pp. 155-160, 2009.

[36] M. P. Monopoli, D. Walczyk, A. Campbell et al., "Physicalchemical aspects of protein corona: relevance to in vitro and in vivo biological impacts of nanoparticles," Journal of the American Chemical Society, vol. 133, no. 8, pp. 2525-2534, 2011.

[37] S. C. Tilton, N. J. Karin, A. Tolic et al., “Three human cell types respond to multi-walled carbon nanotubes and titanium dioxide nanobelts with cell-specific transcriptomic and proteomic expression patterns," Nanotoxicology, vol. 8, no. 5, pp. 533-548, 2014.

[38] F. Sambale, A. Lavrentieva, F. Stahl et al., "Three dimensional spheroid cell culture for nanoparticle safety testing," Journal of Biotechnology, vol. 205, pp. 120-129, 2015.

[39] C. McCracken, Z. Andrew, D. A. Knight, P. K. Dutta, and W. James Waldman, "Minimal intestinal epithelial cell toxicity in response to short- and long-term food-relevant inorganic nanoparticle exposure," Chemical Research in Toxicology, vol. 26, no. 10, pp. 1514-1525, 2013.

[40] R. F. Hamilton, N. Wu, C. Xiang et al., "Synthesis, characterization, and bioactivity of carboxylic acid-functionalized titanium dioxide nanobelts," Particle and Fibre Toxicology, vol. 11, no. 1, article 43, 2014.

[41] J. Wang and Y. Fan, "Lung injury induced by $\mathrm{TiO}_{2}$ nanoparticles depends on their structural features: size, shape, crystal phases, and surface coating," International Journal of Molecular Sciences, vol. 15, no. 12, pp. 22258-22278, 2014.

[42] A. Nemmar, K. Melghit, and B. H. Ali, “The acute proinflammatory and prothrombotic effects of pulmonary exposure to rutile $\mathrm{TiO}_{2}$ nanorods in rats," Experimental Biology and Medicine, vol. 233, no. 5, pp. 610-619, 2008.

[43] D. W. Porter, N. Wu, A. F. Hubbs et al., "Differential mouse pulmonary dose and time course responses to titanium dioxide nanospheres and nanobelts," Toxicological Sciences, vol. 131, no. 1, pp. 179-193, 2013.

[44] J. C. Bonner, R. M. Silva, A. J. Taylor et al., "Interlaboratory evaluation of rodent pulmonary responses to engineered nanomaterials: the NIEHS nano GO consortium," Environmental Health Perspectives, vol. 121, no. 6, pp. 676-682, 2013. 
[45] R. F. Hamilton Jr., N. Wu, D. Porter, M. Buford, M. Wolfarth, and A. Holian, "Particle length-dependent titanium dioxide nanomaterials toxicity and bioactivity," Particle and Fibre Toxicology, vol. 6, article 35, 2009.

[46] E. Huerta-García, S. G. Márquez-Ramírez, M. d. RamosGodinez et al., "Internalization of titanium dioxide nanoparticles by glial cells is given at short times and is mainly mediated by actin reorganization-dependent endocytosis," NeuroToxicology, vol. 51, pp. 27-37, 2015.

[47] J. Liu, X.-F. Huang, L.-J. Lu, M.-X. Li, J.-C. Xu, and H.-P. Deng, "Turbiscan Lab Expert analysis of the biological demulsification of a water-in-oil emulsion by two biodemulsifiers," Journal of Hazardous Materials, vol. 190, no. 1-3, pp. 214-221, 2011.

[48] M. X. Quintanilla-Carvajal, L. S. Meraz-Torres, L. AlamillaBeltrán et al., "Morphometric characterization of spray-dried microcapsules before and after tocopherol extraction," Revista Mexicana de Ingeniería Química, vol. 10, no. 2, pp. 301-312, 2011.

[49] D. J. Gould, T. J. Vadakkan, R. A. Poche, and M. E. Dickinson, "Multifractal and lacunarity analysis of microvascular morphology and remodeling," Microcirculation, vol. 18, no. 2, pp. 136-151, 2011.

[50] B. B. Chaudhuri and N. Sarkar, "Texture segmentation using fractal dimension," IEEE Transactions on Pattern Analysis and Machine Intelligence, vol. 17, no. 1, pp. 72-77, 1995.

[51] E. R. Olsen, R. D. Ramsey, and D. S. Winn, "A modified fractal dimension as a measure of landscape diversity," Photogrammetric Engineering \& Remote Sensing, vol. 59, no. 10, pp. 1517-1520, 1993.

[52] M. S. Grunér, U. Kauscher, M. B. Linder, and M. P. Monopoli, "An environmental route of exposure affects the formation of nanoparticle coronas in blood plasma," Journal of Proteomics, 2015.

[53] L. Sánchez-Segura, D. I. Téllez-Medina, S. Evangelista-Lozano et al., "Morpho-structural description of epidermal tissues related to pungency of Capsicum species," Journal of Food Engineering, vol. 152, pp. 95-104, 2015.

[54] L. Song, K. Yang, W. Jiang, P. Du, and B. Xing, "Adsorption of bovine serum albumin on nano and bulk oxide particles in deionized water," Colloids and Surfaces B: Biointerfaces, vol. 94, pp. 341-346, 2012.

[55] Y.-H. Park, S. H. Jeong, S. M. Yi et al., "Analysis for the potential of polystyrene and $\mathrm{TiO}_{2}$ nanoparticles to induce skin irritation, phototoxicity, and sensitization," Toxicology in Vitro, vol. 25, no. 8, pp. 1863-1869, 2011.

[56] P. Fernández-Ibáñez, J. Blanco, S. Malato, and F. J. de las Nieves, "Application of the colloidal stability of $\mathrm{TiO}_{2}$ particles for recovery and reuse in solar photocatalysis," Water Research, vol. 37, no. 13, pp. 3180-3188, 2003.

[57] M. D. Chadwick, J. W. Goodwin, E. J. Lawson, P. D. A. Mills, and B. Vincent, "Surface charge properties of colloidal titanium dioxide in ethylene glycol and water," Colloids and Surfaces A: Physicochemical and Engineering Aspects, vol. 203, no. 1-3, pp. 229-236, 2002.

[58] E. Papirer, E. Walter, A. Vidal, and B. Siffert, "Adsorption of stearic acid and diethylhexyl phosphate on magnetic metallic iron pigments: electrical surface charging and adsorption competition," Journal of Colloid and Interface Science, vol. 187, no. 2, pp. 529-538, 1997.

[59] J. M. Berg, A. Romoser, N. Banerjee, R. Zebda, and C. M. Sayes, "The relationship between $\mathrm{pH}$ and zeta potential of $30 \mathrm{~nm}$ metal oxide nanoparticle suspensions relevant to in vitro toxicological evaluations," Nanotoxicology, vol. 3, no. 4, pp. 276283, 2009.

[60] M. T. Celis, J. O. Callaghan, A. Forgiarini, P. Rosenzweig Levy, and L. H. García-Rubio, "Effect of nano particles on properties of suspensions," Revista Ciencia e Ingeniería, vol. 36, no. 1, pp. 19-30, 2015.

[61] D. A. Walker, E. K. Leitsch, R. J. Nap, I. Szleifer, and B. A. Grzybowski, "Geometric curvature controls the chemical patchiness and self-assembly of nanoparticles," Nature Nanotechnology, vol. 8, no. 9, pp. 676-681, 2013.

[62] J. Jiang, G. Oberdörster, and P. Biswas, "Characterization of size, surface charge, and agglomeration state of nanoparticle dispersions for toxicological studies," Journal of Nanoparticle Research, vol. 11, no. 1, pp. 77-89, 2009.

[63] V. Talanquer, "Al azar y de uno en uno," in Fractus, Fracta, Fractal: Fractales, de Laberintos y Espejos, pp. 66-72, Fondo de Cultura Económica, Mexico City, Mexico, 1996.

[64] T. P. J. Linsinger, Q. Chaudhry, V. Dehalu et al., "Validation of methods for the detection and quantification of engineered nanoparticles in food," Food Chemistry, vol. 138, no. 2-3, pp. 1959-1966, 2013.

[65] C. Cano-Sarmiento, A. Monroy-Villagrana, L. Alamilla-Beltrán et al., "Micromorphometric characteristics of $\alpha$-tocopherol emulsions obtained by microfluidization," Revista Mexicana de Ingeniería Química, vol. 13, no. 1, pp. 201-212, 2014.

[66] A. Grenha, B. Seijo, and C. Remuñán-López, "Microencapsulated chitosan nanoparticles for lung protein delivery," European Journal of Pharmaceutical Sciences, vol. 25, no. 4-5, pp. 427-437, 2005.

[67] K. Yin Win and S.-S. Feng, "Effects of particle size and surface coating on cellular uptake of polymeric nanoparticles for oral delivery of anticancer drugs," Biomaterials, vol. 26, no. 15, pp. 2713-2722, 2005.

[68] R. C. Stearns, J. D. Paulauskis, and J. J. Godleski, "Endocytosis of ultrafine particles by A549 cells," American Journal of Respiratory Cell and Molecular Biology, vol. 24, no. 2, pp. 108-115, 2001.

[69] J. S. Gebauer, M. Malissek, S. Simon et al., "Impact of the nanoparticle-protein corona on colloidal stability and protein structure," Langmuir, vol. 28, no. 25, pp. 9673-9679, 2012.

[70] V. Freyre-Fonseca, N. L. Delgado-Buenrostro,, Y. I. Chirino, and G. F. Gutiérrez-López, "Safety studies of metal oxide nanoparticles used in food industry," in Food Nanoscience and Nanotechnology, H. Hernandez-Sánchez and G. F. Gutiérrez López, Eds., Food Engineering Series, pp. 243-265, Springer, New York, NY, USA, 2015. 

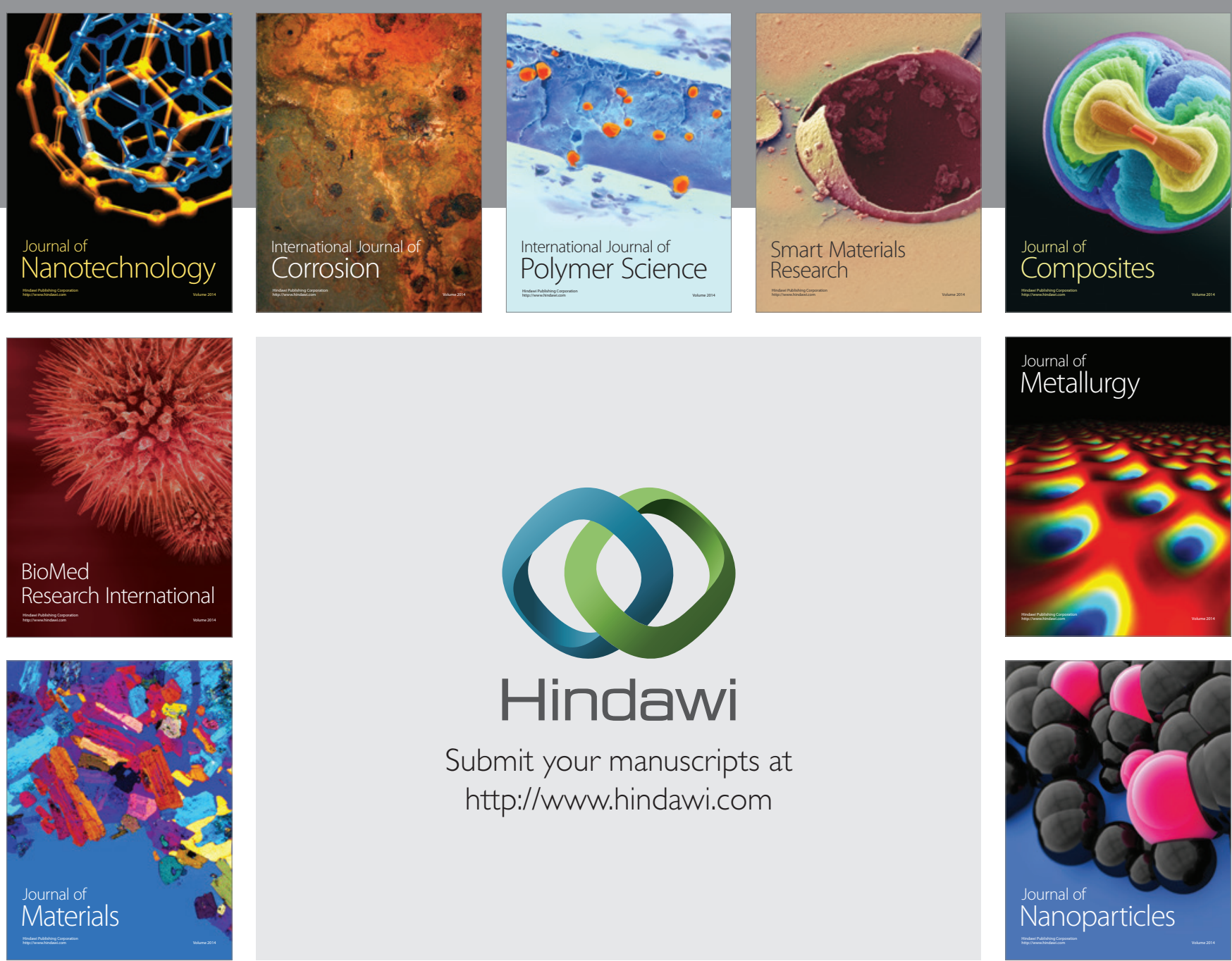

\section{Hindawi}

Submit your manuscripts at

http://www.hindawi.com

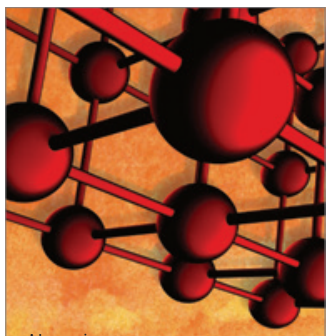

Materials Science and Engineering
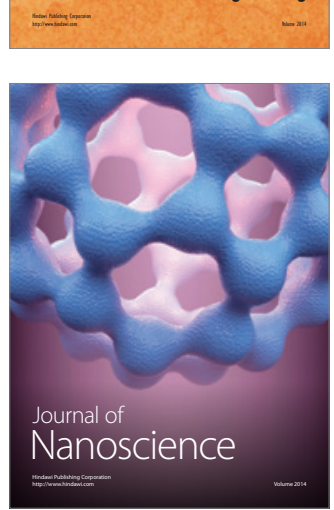
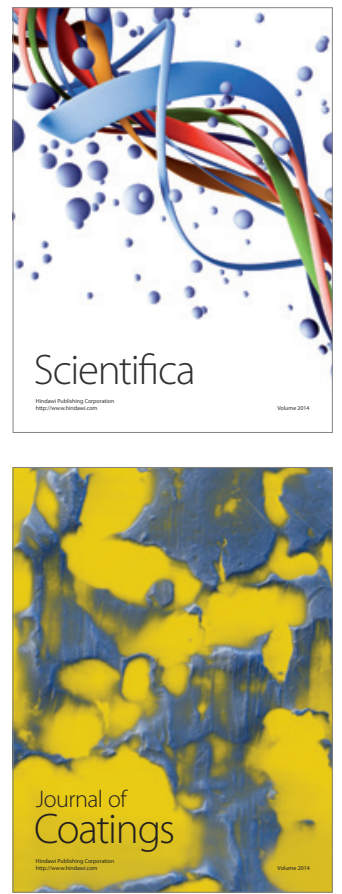
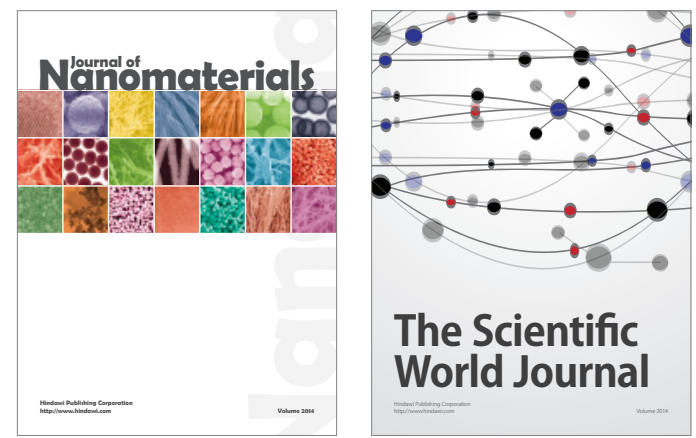

The Scientific World Journal
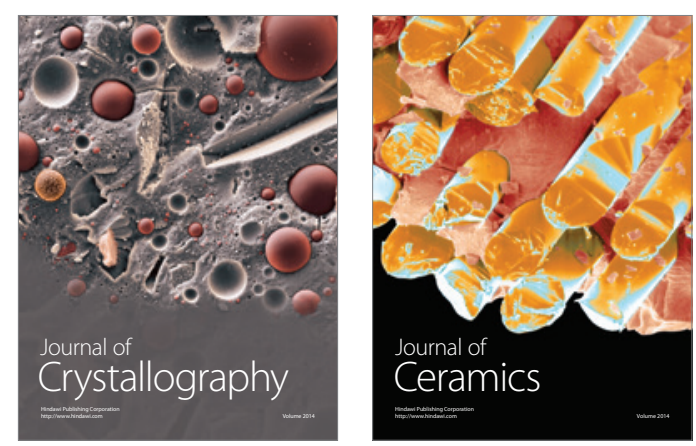
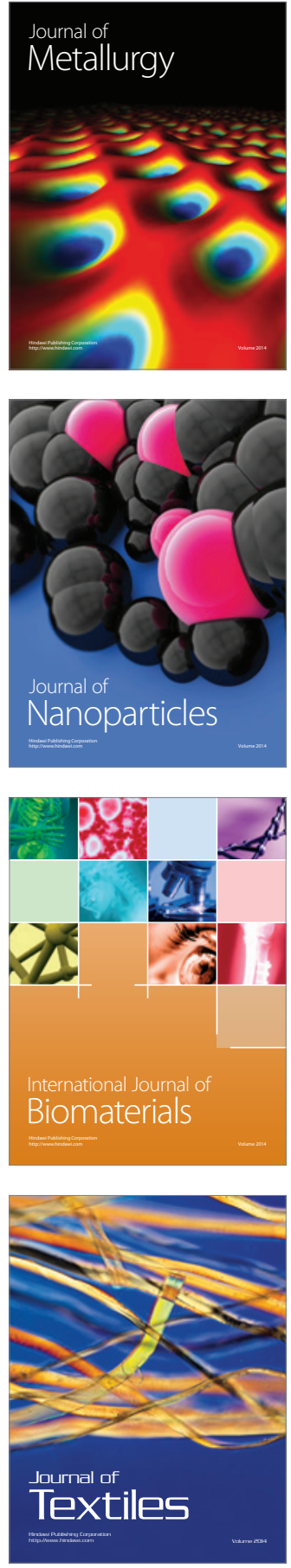